\title{
(UN)NATURALLY LOW?
}

\section{SEQUENTIAL MONTE}

CARLO TRACKING OF

\section{THE US NATURAL}

\section{INTEREST RATE}

by Marco J. Lombardi and Silvia Sgherri

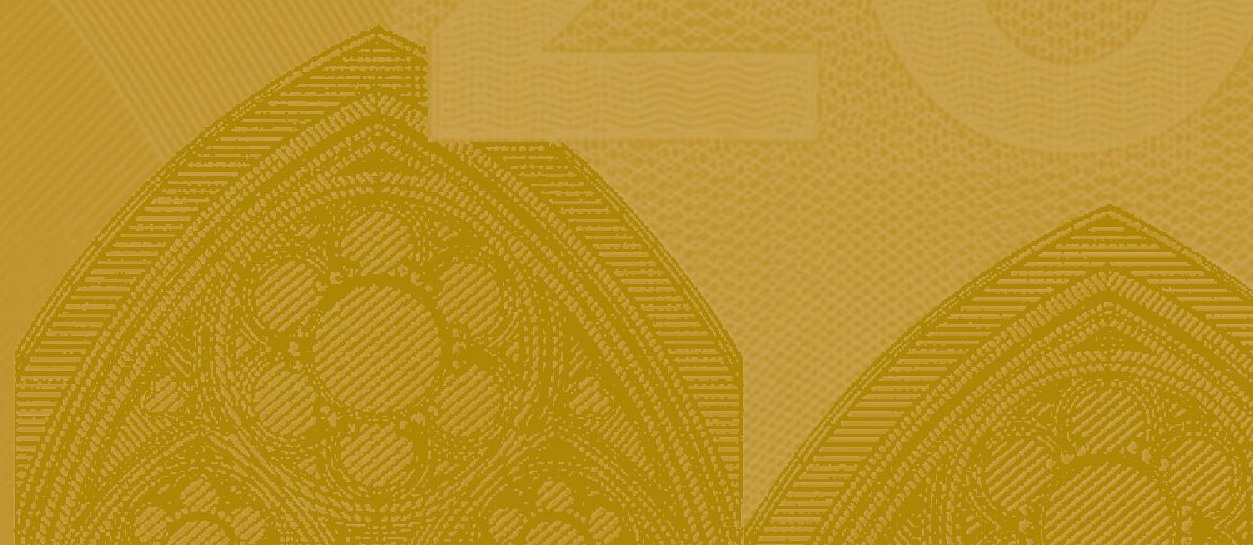


(UN)NATURALLY LOW? SEQUENTIAL MONTE CARLO TRACKING OF THE US NATURAL INTEREST RATE

\author{
by Marco J. Lombardi ${ }^{2}$ \\ and Silvia Sgherri ${ }^{3}$
}

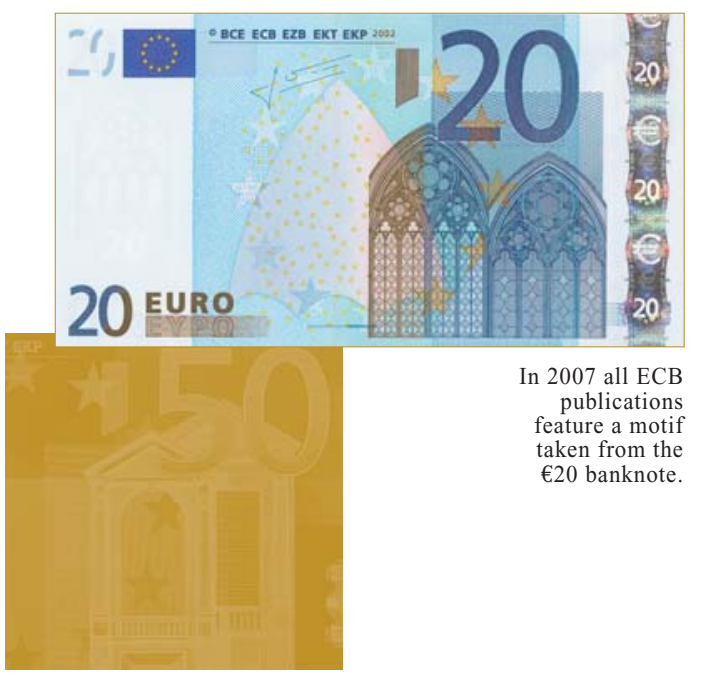

This paper can be downloaded without charge from http://www.ecb.int or from the Social Science Research Network electronic library at http://ssrn.com/abstract_id $=1003969$.

\footnotetext{
I To a large extent, the paper was written while both authors were at the European Central Bank. We thank Gianni Amisano and Matteo Ciccarelli for useful suggestions and Günter Coenen, Ricardo Mestre, Frank Schorfheide, Frank Smets, and Michael Woodford for insightful feedback on a preliminary version of this paper. We are also grateful for comments to seminars participants at ECB and DNB, the 2006 Conference on Computation in Economics and Finance, the 17th EC ${ }^{2}$ Conference, the 2nd Italian Congress of Econometrics and Empirical Economics, and the Royal Economic Society Annual Conference. The views expressed in this paper are personal and do not reflect those of any policy institution. The usual disclaimers apply. 2 University of Pisa, Lungarno Pacinotti 43, 56 I 26 Pisa, Italy; e-mail: mjl@ec.unipi.it 3 De Nederlandsche Bank and International Monetary Fund; Postal address: De Nederlandsche Bank, Postbus 98 , 1000 AB Amsterdam, Netherlands; e-mail: s.sgherri@dnb.nl
} 
(C) European Central Bank, 2007

\section{Address}

Kaiserstrasse 29

60311 Frankfurt am Main, Germany

Postal address

Postfach 160319

60066 Frankfurt am Main, Germany

Telephone

+496913440

Internet

http://www.ecb.europa.eu

Fax

+496913446000

Telex

411144 ecb d

All rights reserved.

Any reproduction, publication and reprint in the form of a different publication, whether printed or produced electronically, in whole or in part, is permitted only with the explicit written authorisation of the ECB or the author(s).

The views expressed in this paper do not necessarily reflect those of the European Central Bank.

The statement of purpose for the ECB Working Paper Series is available from the ECB website, http://www.ecb.europa. eu/pub/scientific/wps/date/html/index. en.html

ISSN 1561-0810 (print)

ISSN 1725-2806 (online) 


\section{CONTENTS}

Abstract 4

Non-technical summary 5

1 Introduction 6

2 A generalized "Neo-Wicksellian" framework 8

2.1 Demand side 9

2.2 Supply side I|

2.3 Monetary policy I4

2.4 Model solution 15

2.5 Prior specification 16

3 Likelihood evaluation and Bayesian estimation 17

3.1 A sequential Monte Carlo approach $\quad 18$

3.2 Parameters estimates 20

3.3 Out-of-sample forecasts 22

4 Empirical results 22

4.1 Structural parameters: posterior distributions

4.2 Unobservable state variables:

A real-time policy assessment

4.3 Out-of-sample forecasts and model evaluation

5 Conclusions and prospects 30

References 33

Tables and figures 38

European Central Bank Working Paper Series 48 


\begin{abstract}
Following the 2000 stockmarket crash, have US interest rates been held "too low" in relation to their natural level? Most likely, yes. Using a structural neo-Keynesian model, this paper attempts a real-time evaluation of the US monetary policy stance while ensuring consistency between the specification of price adjustments and the evolution of the economy under flexible prices. To do this, the model's likelihood function is evaluated using a Sequential Monte Carlo algorithm providing inference about the time-varying distribution of structural parameters and unobservable, nonstationary state variables. Tracking down the evolution of underlying stochastic processes in real time is found crucial (i) to explain postwar Fed's policy and (ii) to replicate salient features of the data.
\end{abstract}

JEL Classification Numbers: E43, C11, C15

Keywords: Natural Interest Rate; DSGE Models; Bayesian Analysis; Particle Filters 


\section{Non-technical summary}

After the 2000 stockmarket bubble burst, the Fed has successfully managed to reduce business cycle volatility (resulting in the mildest US recession ever!) by reducing short-term rates to a 45-year low of 1 percent, while effectively convincing the bond markets that rates would have been kept so low for a considerable period. Yet, it remains an open question whether or not the Fed has cut interest rates by "too much" and left them low for "too long" in relation to the current economic conditions. Possibly, the exceptionally low cost of capital-at a time when the expected worldwide return on capital has likely increased-might have encouraged excessive borrowing, allowing financial imbalances to build up.

Inferring the stance of monetary policy from prevailing interest rates requires some sort of benchmark. Economists tend to assume that such a benchmark role is played by the equilibrium, or "natural," real rate of interest. Put simply, the natural real rate of interest is the rate that keeps output at its potential and inflation stable, once any shocks to the economy have played out. According to this concept, one can thus gauge the stance of, say, the US monetary policy by comparing the actual level of the federal fund rate with the natural rate. Yet, to make life tricky for both policymakers and market participants, the natural rate of interest is not observable and may vary over time, in line with changes in the rate of return on capital or households' rate of time preference. If these movements are sufficiently large, any constant long-term average would be a poor predictor of the natural rate of interest.

By drawing on a structural model featuring explicit theoretical foundations, our paper proposes an original econometric approach to estimate the evolution of an economy under equilibrium conditions. The methodology makes it possible to track down and interpret the different sources of variation and uncertainty in interest rate setting - such as shifts in labour productivity, preference shocks, or households' degree of risk aversion - with sufficient precision and in real time. Our estimates show how the Fed - to deal with the economic downturn following the stock market crash - has been driving the cost of capital significantly below the natural rate for over four years. The results also provide some support to the belief that postwar US inflation's rise and fall was due to Fed's inability to disentangle-in a timely mannertransitory from permanent shifts in productivity. In fact, over 85 percent of the uncertainty surrounding future monetary policy stance is found to stem from imprecision surrounding inferences of the underlying equilibrium position. 


\section{Introduction}

After the US stockmarket bubble burst, the Fed has successfully managed to reduce business cycle volatility by reducing short-term rates to a 45-year low of 1 percent, while effectively convincing the bond markets that rates would have been kept so low for a considerable period. The question is to determine whether in 2001-03 the Fed has cut interest rates by "too much" and left them low for "too long" in relation to their underlying equilibrium level. Although optimal monetary policy is not associated with keeping the actual real rate close to its "normal" level on a period-by-period basis, a prolonged period of exceptionally low cost of capital-at a time when the expected return on capital has likely increased-might have encouraged excessive borrowing, contributing to the buildup of financial imbalances.

Inferring the stance of monetary policy from prevailing interest rates requires some sort of benchmark. Following Wicksell's seminal idea, economists tend to assume that such a benchmark role is played by the natural real rate of interest. Put simply, the natural real rate of interest is the rate that keeps output at its potential and inflation stable, once any shocks to the economy have played out. According to this concept, one can thus gauge the stance of, say, the Fed's monetary policy by comparing the actual level of the federal fund rate with the nominal natural rate. If the rate set by the central bank is lower than the natural rate, the economy and inflation would be expected to accelerate, as there will be excessive investment and borrowing, while households will not save enough. Conversely, if the Fed keeps interest rates above the natural rate, policy would rein in the economy and inflation would eventually slow.

Yet, to make life tricky for both policymakers and market participants, the natural rate of interest is not observable and may vary over time, in line with changes in the rate of return on capital or households' rate of time preference. There are indeed reasons to think that the Wicksellian rate may have shifted over the last decade. The surge in productivity growth owing to the information technology revolution is likely to have boosted expectations about future profits and investment opportunities, moving upwards the demand curve for investment funds, ceteris paribus. Meanwhile, in industrial countries, households seem to have become more impatient and decided that they need to save less than they used to, on the belief that rising asset and house prices will provide them with adequate resources to finance their retirement. As a result, the so-called IS (Investment=Saving) curve - the equilibrium line showing the negative relationship between spending and real interest rate-may have moved rightwards, implying a higher natural rate of interest for any level of potential output. Structural forces- 
such as enhanced competition from emerging markets, deregulation, and faster productivity growth - may have also helped to hold down (the equilibrium level of) inflation, whilst central banks' success in taming inflation (around such an equilibrium level) has anchored inflationary expectations. This has meant that monetary policy can now be eased more freely to deal with economic fluctuations, provided that inflation remains subdued.

From a theoretical perspective, tracking down the evolution of the natural rate of interest requires to pin down the behavior of the economy under equilibrium conditions. In our paper, the problem is tackled within Woodford's (2003) "neo-Wicksellian" framework, which has the property of ensuring consistency between the specification of price adjustments and the (unobservable) behavior of the economy under flexible prices. ${ }^{1}$ Specifically, the model entails rational expectations and neo-Keynesian price rigidities, while guaranteeing a zero output gap in steady state, in compliance with the natural rate hypothesis. Reconciling short-term and equilibrium dynamics becomes particularly relevant in system estimation. In this context, each change to the specification of price adjustments affects the likelihood-maximizing vector of structural parameters which - together with the dynamics and the distributions of shocks - determine the (unobservable) behavior of the economy under flexible prices.

Originally, our prototypical dynamic optimizing sticky-price model has been generalized along three important dimensions. First, it accounts for possible nonstationarity in the steadystate level of inflation and real output. Second, it allows for shifts in the underlying stochastic processes, as well as in the parameterization of the model. Third, it has been estimated in real time, e.g. by using observable, non-detrended data which are readily available at the time they are needed. ${ }^{2}$ To do this, the model's likelihood function is evaluated using a Sequential Monte Carlo algorithm, providing joint estimates of the structural parameters and the unobservable, time-varying, nonstationary state variables. The idea beneath this approach is to represent any probability law by a large number of random samples, or particles, evolving over time on the

\footnotetext{
${ }^{1}$ Notable examples of dynamic, optimizing models examining the behaviour of the natural levels of output and interest are McCallum and Nelson (1999), Rotemberg and Woodford (1999), Galí, López-Salido, Vallés (2003), Woodford (2003), Giammarioli and Valla (2003), Neiss and Nelson (2003), Smets and Wouters (2003), Amato and Laubach (2004), Andrés, López-Salido, Nelson (2005).

${ }^{2}$ The issue of real-time estimation of unobservable equilibrium variables has received increasing attention in the context of monetary policy analysis. See, among others, Laubach (2001), Larsen and McKeown (2002), Orphanides and Williams (2002), Laubach and Williams (2003), Basdevant, Björksten, and Karagedikli (2004), Cuaresma, Gnan, and Ritzberger-Grunenwald (2004), Mésonnier and Renne (2006), Sevillano and Simon (2004), Garnier and Wilhelmsen (2005). Overall, real-time measures of the time-varying natural rate of interest-like those of the equilibrium level of output, unemployment, and inflation - are found to be highly imprecise, limiting their relevance for policy.
} 
basis of a simulation-based updating scheme, so that new observations are incorporated in the filter as they become available. By tracking down the whole distribution of the natural rate of interest in real time, it is possible to interpret the different sources of variation and uncertainty in interest rate setting - such as shifts in labour productivity, volatility of preference shocks, or households' degree of risk aversion - in a timely and helpful manner.

To anticipate our conclusions, our estimates show how the Fed-to deal with the slowdown following the stock market crash - has been cutting interest rates aggressively, driving the cost of capital significantly below the natural rate for over four years. In the most recent quarters, however, repeated monetary policy tightening has managed to correct this disequilibrium while slowing down growth. Yet, the inflation gap is found to be still positive at the end of 2006. From a positive perspective, our findings are broadly in line with Cogley and Sbordone's (2005) general argument that ignoring time variation in the underlying evolution of the economy under flexible prices may alter the estimates of structural parameters. While the volatility of preference shocks is likely to have fallen over time, structural pricing parameters are essentially time-invariant once shifts in trend growth and inflation are also accounted for. From a normative perspective, our results provide some support to the hypothesis that-over the postwar period-Fed's inability to promptly disentangle permanent from transitory shifts in productivity may have translated into persistent movements in the inflation rate itself. By the same token, uncertainty about future interest rate settings is found to be primarily due to vagueness in the estimate of the underlying stochastic equilibrium rather than to imprecision about the structural parameterization of the model economy or the policy rule.

The rest of the paper is organized as follows. Section 2 lays down a dynamic stochastic model consistent with the neo-Wicksellian approach to price determination. Section 3 presents the methodology adopted to evaluate the likelihood of such a model, estimate posterior densities for its parameters, and track down the time-varying distribution of its unobservable state variables. Section 4 discusses estimation and forecasting results, while Section 5 concludes the paper by providing an outlook on future work.

\section{A Generalized "Neo-Wicksellian" Framework}

Our structural model has a prototypical rational expectations specification, similar to the one used by Boivin and Giannoni (2003), Giannoni and Woodford (2005), and described in Woodford (2003). On the demand side, we take into account habit persistence in the level of aggregate expenditure, assuming that for each household $i$ in period $t$, utility depends not only on current 
expenditure, but also on the level of expenditure in the previous period. On the supply side, we allow for price indexation for firms that are not allowed to set their price optimally in a given period, in order to generate more realistic level of inflation inertia. ${ }^{3}$ The setup is then originally enriched by letting in exogenous non-stationary processes - describing (labor) productivity and target inflation dynamics, respectively — as well as idiosyncratic demand, supply, and policy shocks.

\subsection{Demand Side}

We assume a model economy producing a continuum of goods indexed by $j$ and populated by a continuum of households indexed by $i$, uniformely distributed over the $[0,1]$ interval. By considering the limiting case of a cashless economy - and thereby abstracting from real balances - each household $i$ seeks to maximize the following infinite discounted sum of future utilities:

$$
E_{t}\left\{\sum_{\tau=t}^{\infty} \beta^{\tau-t} \varepsilon_{\tau}^{u}\left[\frac{1}{1-\sigma}\left(C_{\tau}^{i}-\eta C_{\tau-1}^{i}\right)^{1-\sigma}-\frac{1}{1+\varrho} H_{\tau}^{i}(j)^{1+\varrho}\right]\right\}
$$

where $C_{\tau}^{i}$ is an index of the household's consumption of the differentiated goods supplied at $t$ and $H_{\tau}^{i}(j)$ denotes the amount of hours supplied by each household $i$ for the production of each good $j$. In addition, $\beta=1 /(1+\bar{r}) \in(0,1)$ is the households' discount factor, $\sigma$ is the coefficient of relative risk aversion or the inverse of the intertemporal elasticity of substitution, and $\varrho$ represents the inverse of the elasticity of work effort with respect to the real wage. The parameter $0 \leq \eta \leq 1$ measures the degree of habit formation in consumption. Consumers' utility hence depends positively on deviations of consumption $C_{\tau}^{i}$ from an existing stock $\eta C_{\tau-1}^{i}$, and negatively on the total labor supplied. ${ }^{4}$ Equation (1) also contains a shock to the discount rate that affects the intertemporal preferences of households, $\varepsilon_{\tau}^{u}$, distributed as a log-normal with mean equals to 1 .

Households maximize their objective function (1) subject to an intertemporal budget constraint that is given by:

$$
b_{\tau} \frac{B_{\tau}^{i}}{P_{\tau}}=\frac{B_{\tau-1}^{i}}{P_{\tau}}+\left(W_{\tau}^{i} H_{\tau}^{i}+A_{\tau}^{i}\right)-C_{\tau}^{i}
$$

\footnotetext{
${ }^{3}$ This extension has been recently proposed by Christian, Eichenbaum, and Evans (2005). Inflation indexation has been also used, for instance, in Smets and Wouters (2005), Milani (2005), and Andrés et al. (2005).

${ }^{4}$ The consumption habit is assumed here to depend on the household's own past level of expenditure, and not on that of other households.
} 
implying that households hold their financial wealth in the form of one-period securities, $B_{T}$, having price $b_{T}$. Total income - consisting of labor income and the net cash inflow from participating in state-contingent securities, i.e., $Y_{\tau}^{i}=W_{\tau}^{i} H_{\tau}^{i}+A_{\tau}^{i}$-is solely used for consumption purposes. ${ }^{5}$ Under the assumption of complete financial markets and efficient risk sharing, state-contingent securities would insure households against household-specific fluctuations in labor income, so that each household faces an identical intertemporal budget constraint and an identical marginal utility of total income. As a result, the superscript $i$ can be omitted without loss of generality.

With habit formation, the maximization of the objective function (1) subject to the budget constraint (2) with respect to consumption can therefore be written as:

$$
\lambda_{t}=\varepsilon_{t}^{u}\left(C_{t}-\eta C_{t-1}\right)^{-\sigma}-\eta \beta\left[\varepsilon_{t+1}^{u}\left(C_{t+1}-\eta C_{t}\right)^{-\sigma}\right]
$$

where the marginal utility of real income at time $t$ (i.e., the Lagrange multiplier for the budget constraint, $\lambda_{t}$ ) depends upon both today's and tomorrow's expected marginal utility of consumption, as well as preference shocks occurring at time $t$ and $t+1$. In addition, the marginal utility of income satisfies the first order condition for the optimizing consumer's problem with respect to bonds holdings, yielding:

$$
\lambda_{t}=\beta E_{t}\left[\lambda_{t+1}\left(1+i_{t}\right) \frac{P_{t}}{P_{t+1}}\right]
$$

where $\left(1+i_{t}\right)=\frac{1}{b_{t}}$ denotes the riskless one-period (gross) nominal rate of return on bonds and $E_{t}\left[\frac{P_{t+1}}{P_{t}}\right]=\left(1+E_{t} \pi_{t+1}\right)$ defines the expected (gross) rate of inflation. Using (3) to substitute for the $\lambda^{\prime} \mathrm{s}$ in (4), we can thus derive the generalized Euler equation in the presence of habit formation, namely:

$$
\frac{\varepsilon_{t}^{u}\left(C_{t}-\eta C_{t-1}\right)^{-\sigma}-\eta \beta E_{t}\left[\varepsilon_{t+1}^{u}\left(C_{t+1}-\eta C_{t}\right)^{-\sigma}\right]}{E_{t}\left[\varepsilon_{t+1}^{u}\left(C_{t+1}-\eta C_{t}\right)^{-\sigma}\right]-\eta \beta E_{t}\left[\varepsilon_{t+2}^{u}\left(C_{t+2}-\eta C_{t+1}\right)^{-\sigma}\right]}=\beta\left[\frac{\left(1+i_{t}\right)}{\left(1+E_{t} \pi_{t+1}\right)}\right]
$$

In our basic neo-Wicksellian closed economy, all interest-sensitive private expenditure is modeled as if it were nondurable consumption, thereby abstracting from the effects of variations in private expenditure on the evolution of productive capacity. This simplification has three implications. Firstly, given our fiscal policy assumption, the aggregate equilibrium relation $C_{t}=Y_{t}$ holds; secondly, the parameter $\sigma^{-1} \equiv \frac{-U_{c}}{C^{*} U_{c c}}>0$ indicates the intertemporal

\footnotetext{
${ }^{5}$ Assuming that the goverment implements a Ricardian fiscal policy while levying lump sum taxes, fiscal policy can be ignored given that it has no effect on model aggregates.
} 
substitutability of private expenditure as a whole, rather than that of nondurable consumption alone (Rotemberg and Woodford, 1997); and, thirdly, the "habit persistence" considered here can be deemed as a proxy for adjustment costs in both investment and consumption spending, rather than solely as a description of household preferences with regard to personal consumption. Along a balanced growth path in which hours worked are constant, aggregate expenditure is growing at its equilibrium rate-say $g^{*}$-and the marginal utility of real expenditure is falling at rate $\left(g^{*}\right)^{\sigma}$, log-linearization of Euler equation (5) around steady state yields a generalization of the IS relation of the form:

$$
\widetilde{y}_{t}=E_{t} \widetilde{y}_{t+1}-[\sigma(1-\eta \beta)]^{-1}\left[\widehat{i}_{t}-E_{t} \widehat{\pi}_{t+1}-\bar{r}\right]+\widetilde{\zeta}_{t}^{u}
$$

where

$$
\begin{aligned}
\widetilde{y}_{t} & =\left(\widehat{y}_{t}-\eta \widehat{y}_{t-1}\right)-\eta \beta E_{t}\left(\widehat{y}_{t+1}-\eta \widehat{y}_{t}\right) \\
\widetilde{\zeta}_{t}^{u} & =[\sigma(1-\eta \beta)]^{-1}\left[\zeta_{t}^{u}-\eta \beta E_{t}\left(\zeta_{t+1}^{u}\right)\right] .
\end{aligned}
$$

Here, $\zeta_{t}^{u}$ denotes normally distributed aggregate demand shocks and hatted variables indicate (log-)deviations from corresponding (time-varying) equilibrium levels, e.g.:

$$
\begin{aligned}
& \widehat{y}_{t}=y_{t}-y_{t}^{*} \\
& \widehat{i}_{t}=i_{t}-i_{t}^{*} \\
& \widehat{\pi}_{t}=\pi_{t}-\pi_{t}^{*}
\end{aligned}
$$

Note that as $\eta \longrightarrow 0$, expression (5) collapses to the standard Euler equation for consumption, while expression (6) reduces to the well-known log-linear forward-looking IS curve, where the output gap is expressed in terms of deviations of actual output from its equilibrium path.

\subsection{Supply Side}

We assume a continuum of monopolistic competitive firms indexed by $j$ and uniformely distributed over the $[0,1]$ interval. Each firm is a monopolistic supplier of good $j$, which is produced according to the production technology $Y_{t}(j)=Z_{t} H_{t}(j)$,where $H_{t}(j)$ is labor input and $Z_{t}$ describes an exogenous nonstationary productivity process common to all firms. Indicating with $g_{t}=\ln \left(G_{t}\right)$ the stationary growth rate of the productivity process, with $\zeta_{t}^{z}$ idiosyncratic 
innovations to its level, and with $\zeta_{t}^{g}$ idiosyncratic innovations to its growth rate, the log of the productivity process, $z_{t}=\ln \left(Z_{t}\right)$, evolves according to:

$$
\begin{aligned}
& \ln \left(Z_{t}\right)=\ln \left(Z_{t-1}\right)+\ln \left(G_{t-1}\right)+\zeta_{t}^{z} \\
& \ln \left(G_{t}\right)=\vartheta \ln \left(G_{t-1}\right)+(1-\vartheta) \ln \left(G^{*}\right)+\zeta_{t}^{g}
\end{aligned}
$$

thereby inducing a stochastic trend in aggregate expenditure. As $0 \leq \vartheta<1$, it follows that our model economy evolves along a stochastic growth path, featuring a $g^{*}$ equilibrium rate. The quantity of capital available for the production of each individual good is regarded as fixed, leaving labor as the only variable factor of production. ${ }^{6}$ Labor is hired in a perfectly competitive factor market, at the hourly real wage $W_{t}$.

Monopolistic competitive firms face a common demand curve $Y_{t}(j)=Y_{t}\left(\frac{p_{t}(j)}{P_{t}}\right)^{-\chi}$ for their products, where the parameter $\chi>1$ represents the elasticity of demand for each good $j$. In this context, $Y_{t}=\left[\int_{0}^{1} Y_{t}(j)^{\frac{\chi-1}{\chi}} d j\right]^{\frac{\chi}{x-1}}$ is aggregate output and $P_{t}$ is aggregate price-both taken as given. Hence, all firms face identical maximization problem and, if allowed to choose their own price, set a common price $p_{t}^{*}$.

Following Calvo (1983), however, we suppose that only a fraction $0<(1-\alpha)<1$ of firms are allowed to change their price in a given period, while the remaining fraction $\alpha$ simply adjusts prices according to an indexation rule. In contrast to baseline Calvo price setting, we postulate that those price setters who cannot reset their prices today, have their prices automatically raised by a percentage $0<\gamma<1$, so that $\gamma$ represents the degree of indexation to past inflation.

Under standard properties of the profit function of each supplier $j$, and assuming that profits are discounted using a stochastic discount factor equal —on average - to $\beta$, Woodford (2003) demonstrates that the resulting inflation dynamics can be log-linearized as:

$$
\widehat{\pi}_{t}-\gamma \widehat{\pi}_{t-1}=\beta E_{t}\left(\widehat{\pi}_{t+1}-\gamma \widehat{\pi}_{t}\right)+\mu\left\{\omega \widehat{y}_{t}+[(1-\eta \beta) \sigma] \widetilde{y}_{t}\right\}+\zeta_{t}^{\pi}
$$

where

$$
\mu=\frac{(1-\alpha)(1-\alpha \beta)}{\alpha(1+\chi \omega)}
$$

$\zeta_{t}^{\pi}$ is a white noise exogenous aggregate supply shock, and $\widetilde{y}_{t}, \widehat{y}_{t}$, and $\widehat{\pi}_{t}$ are defined as in (7), (9), and (10), respectively. ${ }^{7}$

\footnotetext{
${ }^{6}$ Woodford (2003) shows that the constant-capital model can be recovered as a limiting case of a model with endogenous capital accumulation, in the limit of very high adjustment costs for investment.

${ }^{7}$ For algebraic details, see Woodford (2003).
} 
Note that, in the presence of habit formation $(\eta>0)$, the log marginal utility of total real income entering the Phillips curve (14) is written as a linear function of $\widetilde{y}_{t}$, rather than simply as a linear function of $\widehat{y}_{t}$ (which would be the case for $\eta=0$ ). ${ }^{8}$ Moreover, indexation to past inflation $(\gamma>0)$ in the form specified in (14) ensures that the NRH is also satified, albeit locally: on average, output equals its potential level for an exogenous steady-state inflation rate - meaning that dynamic indexation only describes temporary fluctuations of the economy around its time-varying equilibrium.

In the absence of nominal rigidities, the equilibrium level of aggregate output is determined by

$$
\ln \left(Y_{t}^{*}\right)=\kappa_{0}+\ln \left(Z_{t}\right)
$$

while its evolution over time is governed by the productivity process described by (12). ${ }^{9}$ It should be stressed that in our modeling framework the concepts of "potential", "equilibrium", "steady-state" and "flexible-price" level of output coincide: they are hence interchangably denoted by $y_{t}^{*}$ and described by the same time-varying, unobservable, nonstationary process, (15), thereby shaping the output gap (9).

The corresponding flexible-price natural real rate of interest (NRI) - the real interest rate in an equilibrium where price rigidities are ruled out and the output gap is zero at all times - is defined as: ${ }^{10}$

$$
\ln \left(1+r_{t}^{*}\right)=\bar{r}+[(1-\eta \beta) \sigma] \ln \left(\frac{\varepsilon_{t}^{u} E_{t}\left[Y_{t+1}^{*}\right]}{E_{t}\left[\varepsilon_{t+1}^{u}\right] Y_{t}^{*}}\right)
$$

with

$$
\ln \left(1+r_{t}^{*}\right) \equiv \ln \left[\frac{\left(1+i_{t}^{*}\right)}{\left(1+\pi_{t+1}^{*}\right)}\right]
$$

\footnotetext{
${ }^{8}$ In the absence of habit formation, the aggregate dynamics of inflation with indexation would reduce to $\widehat{\pi}_{t}-\gamma \widehat{\pi}_{t-1}=\beta E_{t}\left(\widehat{\pi}_{t+1}-\gamma \widehat{\pi}_{t}\right)+\mu(\omega+\sigma) \widehat{y}_{t}+\varepsilon_{t}^{\pi}$, where $(\omega+\sigma)$ measures the elasticity of the average real marginal cost with respect to the aggregate output.

${ }^{9}$ The constant $\kappa_{0}$-which is inversely related to the degree of market distortion, $\chi$-does not affect the law of motion of the aggregate level of output and is, therefore, unidentifiable.

${ }^{10}$ Following Neiss and Nelson (2003), we define the NRI as the equilibrium rate of return that would prevail if the prices had always been flexible in the past and expected to be so in the future. Under this condition, even if the model is extended to allow for endogenous capital accumulation, the existing capital stock (and, thereby, past monetary policy) would not matter for the determination of the NRI.
} 


\subsection{Monetary Policy}

Monetary policy is introduced in the model through a linearized Taylor rule with partial adjustment and time-varying target for inflation:

$$
i_{t}=\rho i_{t-1}+(1-\rho)\left[i_{t}^{*}+\varphi_{1} \widehat{\pi}_{t}+\varphi_{2} \widehat{y}_{t}\right]+\zeta_{t}^{r}
$$

where $\rho$ is the degree of interest rate smoothing, $\varphi_{1}$ and $\varphi_{2}$ denote the long-run interest rate responses to deviations of inflation and output from their respective (time-varying) steady-state levels, while $\zeta_{t}^{r}$ accounts for unanticipated deviations from the systematic monetary policy rule. A similar rule allows for shifts in the equilibrium level of inflation, while the systematic policy responses have not changed over time.

An alternative specification of the monetary rule is also considered, according to which deviations of the policy rate from equilibrium are allowed to adjust for deviations of inflation and output growth from their equilibrium values.

$$
i_{t}=\rho i_{t-1}+(1-\rho)\left[i_{t}^{*}+\varphi_{1} \widehat{\pi}_{t}+\varphi_{2}\left(\widehat{y}_{t}-\widehat{y}_{t-1}\right)\right]+\zeta_{t}^{r}
$$

Several studies on policy rule optimality find that growth rules-such as (19)-tend to be more robust than gap rules-such as (18)-in the face of uncertainty (e.g. mispecification) about the natural level of output (or unemployment). ${ }^{11}$ Our paper compares the performance of these two rules by estimating them in real time, jointly with the evolution of potential output, its growth rate, and their related uncertainty.

Exogenous shifts in the monetary policy target $\pi_{t}^{*}$ are believed to follow a Markov-switching process such as:

$$
\pi_{t}^{*}=\pi_{t-1}^{*}+k_{\pi} * \iota_{t}
$$

whose transition matrix is given by:

$$
\begin{aligned}
& P\left(\iota_{t}=1\right)=p_{u} \\
& P\left(\iota_{t}=-1\right)=p_{d} \\
& P\left(\iota_{t}=0\right)=1-p_{u}-p_{d}
\end{aligned}
$$

given $k_{\pi}=0.50$ percent.

The idea here is to capture true shifts in the objective of the central bank, under the presumption that the central bank target is revised discretely over time with a step of 50 basis

\footnotetext{
${ }^{11}$ See, for instance, Levin, Wieland and Williams (2004).
} 
points. This is a relatively new approach in the literature, as in most cases the target inflation is assumed to follow a Gaussian random walk (see, for example, Amisano and Tristani (2006), Smets and Wouters (2004)). ${ }^{12}$ Clearly, the fact that the transition matrix has only three states might be viewed as a restriction, but this limitation can be easily generalized.

\subsection{Model Solution}

Equations (6) to (23) form a linear rational expectation system in the state variables

$$
\mathbf{x}_{t}=\left[\begin{array}{llllllll}
\widehat{y}_{t} & \widehat{\pi}_{t} & \widehat{r}_{t} & y_{t}^{*} & \pi_{t}^{*} & r_{t}^{*} & g_{t} & \iota_{t}
\end{array}\right]^{\prime}
$$

driven by innovations $\zeta_{t}=\left[\begin{array}{lllll}\zeta_{t}^{u} & \zeta_{t}^{\pi} & \zeta_{t}^{r} & \zeta_{t}^{z} & \zeta_{t}^{g}\end{array}\right]^{\prime}$. This rational expectation system has to be solved and cast in state space before the DSGE model can be estimated. It is important to note that, even though all variables in our model can be re-written in terms of deviations from equilibrium, we do not induce stationarity by constructing a log-linear approximation of the model around the steady-state for the detrended variables (see, for instance, Altig et al. (2002)). Instead, we prefer to take our model directly to readily available, non-detrended data and account for possible shifts in their underlying trends in real time. In this way, we also avoid imposing any co-trending restriction, which are hardly supported by empirical evidence (Canova et al. (1994), Del Negro et al. (2004)). The solution of the rational expectation system hence takes the form:

$$
\mathbf{x}_{t}=F\left(\mathbf{x}_{t-1}, \zeta_{t} ; \theta\right)
$$

with $F$ being a general function of the vector of structural parameters of our DSGE model, $\theta$, defined as:

$$
\theta=\left[\begin{array}{lllllllllllllllll}
\eta & \sigma^{-1} & \gamma & \alpha & \beta & \rho & \varphi_{1} & \varphi_{2} & p_{u} & p_{d} & \vartheta & g^{*} & \sigma_{\zeta^{u}} & \sigma_{\zeta^{\pi}} & \sigma_{\zeta^{r}} & \sigma_{\zeta^{z}} & \sigma_{\zeta^{g}}
\end{array}\right]^{\prime},
$$

where $\sigma_{\zeta^{u}}, \sigma_{\zeta^{\pi}}, \sigma_{\zeta^{r}}, \sigma_{\zeta^{z}}$, and $\sigma_{\zeta^{g}}$ are the standard deviations of the shocks to the aggregate demand, supply, monetary policy, (stochastic) productivity level and corresponding growth rate. $^{13}$

\footnotetext{
${ }^{12}$ We think of our discrete Markov switching process as a quite realistic representation of policymakers' behavior over the spell of a quarter. Nonetheless, the model has been also estimated using a more conventional random walk inflation target. For the sake of brevity, results are omitted, although available upon request.

${ }^{13}$ In order to deal with identification issues, the values of the parameters $\chi$ and $\omega$ have been fixed to 7.52 and .898, respectively, in line with Giannoni and Woodford (2003) and Milani (2005). We are aware that this procedure may create distorsions in the estimated distribution of the remaining parameters, unless the chosen values happen to be the correct ones (Canova and Sala, 2006).
} 
Depending on the parameterization of the structural model, there are three possibilities: no stable rational expectation solution exists; the stable solution is unique (determinacy); or there are multiple stable solutions (indeterminacy). We will focus on the case of determinacy and restrict the parameter space accordingly. For linear models like the one at hand, several solution algorithms are available. ${ }^{14}$ For the subsequent analysis, we use Klein's (2000) generalized Schur form to solve our linearized DSGE model (6) to (23). Within a nonlinear framework, the identification of structural parameters becomes challenging given the nonlinear mapping from the structural form of the DSGE model into its state-space representation. In particular, under these conditions, first-order approximations may not suffice any longer, and higher-order refinement have to be brought into play. ${ }^{15}$

The model is completed by defining a set of measurement equations that relate the elements of $\mathbf{x}_{t}$ to a set of observable variables, $\mathbf{y}_{t}=\left[\begin{array}{lll}y_{t} & \pi_{t} & i_{t}\end{array}\right]^{\prime}$, comprising quarterly data over the period 1957:I to 2006:IV on real GDP, annualized quarterly rate of change of the CPI less food and energy, and the effective federal funds rate. ${ }^{16}$ Namely:

$$
\mathbf{y}_{t}=G\left(\mathbf{x}_{t}, \zeta_{t} ; \theta\right)
$$

The general state-space model (24)-(25) forms the basis for the likelihood estimation of the structural parameters $\theta$, which — together with the distribution of the shocks $\zeta_{t}$-determine the underlying behavior of the economy under flexible prices.

\subsection{Prior Specification}

One of the hardest tasks in implementing Bayesian estimation is how to specify sensible priors about the deep parameters of the model. While, in principle, priors should reflect stong beliefs about the validity of underlying microeconomic theory, in practice most priors are fine-tuned to match important properties of the aggregate data.

Table 1 summarizes information about our priors over the vector of structural parameters $\theta$. For convenience, all parameters are assumed a priori to be independent.

The habit and indexation parameters, $\eta$ and $\gamma$, are assumed to follow beta distributions with mean 0.5 and 0.9 , and standard deviations 0.3 and 0.05 , respectively. The mean prior for the coefficient $\alpha$-governing the degree of price stickiness-is chosen equal to 0.2 based

\footnotetext{
${ }^{14}$ For instance, Blanchard and Kahn (1980), Uhlig (1999), Klein (2000), Christiano (2002), and Sims (2002).

${ }^{15}$ Algorithms to construct second-order accurate solutions to DSGE models have been developed, for instance, by Schmitt-Grohe and Uribe (2004) and Klein (2005). Amisano and Tristani (2006) explore the advantages of using higher order solution methods to study persistence in euro area inflation.

${ }^{16}$ The series were obtained from FRED, the database of the Federal Reserve Bank of Saint Louis.
} 
on micro-evidence on price setting behavior, implying re-optimization of prices approximately every quarter (for instance, Bils and Klenow (2004)). The prior for the degree of interest smoothing in the monetary policy rule, $\rho$, is centered around 0.8 , while the prior means of the feedback coefficients, $\varphi_{1}$, and $\varphi_{2}$, are chosen to match values typically associated with the Taylor rule, namely 1.5 and 0.5 , respectively. To guarantee values in $\mathbb{R}^{+}$, we postulate lognormal distributions for the standard deviation of shocks, $\sigma_{\zeta^{u}}, \sigma_{\zeta^{\pi}}, \sigma_{\zeta^{r}}, \sigma_{\zeta^{z}}$, and $\sigma_{\zeta^{g}}$, whereas for the intertemporal elasticity of substitution, $\sigma^{-1}$, we assume a gamma distribution with mean equal to 0.4, close to the corresponding estimate in Rotemberg and Woodford (1997). In addition, the implied annual discount rate $\bar{r}$ is centered around 2 percent, the root of the autoregressive process characterizing the growth rate of productivity is believed to be distributed around a mean value of 0.8 , while the equilibrium rate of productivity growth has a prior mean of 3 percent per annum. Finally, since we do not have strong prior beliefs for $p_{d}$ and $p_{u}$-lacking previous estimates in the literature - we prefer to represent them through equally centered beta distributions, implying an overall 50 percent probability of switching.

As for the starting values of the state variables, by and large they are chosen based on information at the beginning of the sample. In particular, the prior mean of the year-on-year growth rate of productivity, $\ln \left(G_{0}\right)$, is 4 percent, while the initial target of inflation is taken to be centered at 2 percent. Finally, given the priors for the vector of structural parameters, $\theta$, equation (16) implies a prior mean for the annual NRI around 2.8 percent.

\section{Likelihood Evaluation and Bayesian Estimation}

To fit the solved DSGE model to the vector $\mathbf{y}_{t}$ of observable variables, we employ a Bayesian estimation technique based on the likelihood function generated by the structural system of equations. More specifically, the model's likelihood function is evaluated using a Sequential Monte Carlo algorithm - or particle filter - providing joint estimates of the structural parameters and the unobservable, time-varying, nonstationary state variables.

To our knowledge, this is a very innovative way to bring DSGE models to data. Up to now, in the setting of DSGE models, particle filters have been used to construct the likelihood, but not to perform parameter estimation. This is due to the computational burden in solving the model for each particle and for each time stamp. We propose an indirect way of proceeding, which yields parameter estimates directly from the filtering procedure, through a single solution of the DSGE model for each particle.

Our idea is to impose priors on the structural parameters of our DSGE model, solve it, esti- 
mate the corresponding state-space system using the particle filter recursion, and map back the posterior distribution of the structural rational expectation model's parameters. Specifically:

- Given the set of overidentifying restrictions implied by the model, we impose priors on the vector $\theta$ and map the structural parameter space into the parameter space of the state-space model, say $\phi$;

- The particle filter is then used for inference on the state-space model, where underlying nonstationary processes and static parameters are treated as state variables;

- Each set of $M$ draws from the filtering distribution of the static parameters $\phi$ is then mapped back into the parameter space of the structural model to get the posterior distribution of $\theta$.

The idea of mapping one parameter space into another is somewhat similar to that of indirect inference (Smith (1993), Christiano et al. (2005)), although further work is currently in progress to investigate this parallel. From a technical standpoint, the mapping employed in our analysis implies a direct knowledge of the binding function. Contrary to plain indirect approaches, however, no optimization algorithm is called for by the filtering methodology adopted here, as the estimates of the state-space model do already exhibit the necessary statistical properties. If a unique stable solution exists, the state-space model is derived univocally from the structural economic model: we can thus reasonably expect the misspecification bias to be relatively small.

\subsection{A Sequential Monte Carlo Approach}

The particle filtering approach is an extremely powerful framework for inference in state-space model (Doucet et al. (2000)). Although these methods have originated in the engineering literature (Gordon et al. (1993), Kitagawa (1996)), they have recently been employed also for financial (Pitt and Shephard (1999)) and macroeconomic applications (Fernández-Villaverde and Rubio-Ramírez (2004a, 2004b), An and Schorfheide (2005), Amisano and Tristani (2006)). The idea is to represent the distribution of the state variables by a Monte Carlo approximation constructed via a large number of random samples, or particles, evolving over time on the basis of a simulation-based updating scheme. In this way, new observations are processed by the filter as they become available. Each particle is assigned a weight, which is updated recursively.

Given the state-space model defined by (24)-(25), the filtering problem lies in the determination of $p\left(\mathbf{x}_{t} \mid \mathbf{y}_{1: t}, \phi\right)$. This can be performed in two steps: 
1. Projection:

$$
p\left(\mathbf{x}_{t+1} \mid \mathbf{y}_{1: t}, \phi\right)=\int p\left(\mathbf{x}_{t+1} \mid \mathbf{x}_{t}, \phi\right) p\left(\mathbf{x}_{t} \mid \mathbf{y}_{1: t}, \phi\right) d \mathbf{x}_{t}
$$

2. Updating:

$$
\begin{aligned}
p\left(\mathbf{x}_{t+1} \mid \mathbf{y}_{1: t+1}, \phi\right) & =\frac{p\left(\mathbf{x}_{t+1} \mid \mathbf{y}_{1: t}, \phi\right) p\left(\mathbf{y}_{1: t+1} \mid \mathbf{x}_{t+1}, \phi\right)}{p\left(\mathbf{y}_{1: t+1} \mid \mathbf{y}_{1: t}, \phi\right)} \\
p\left(\mathbf{y}_{t+1} \mid \mathbf{y}_{1: t}, \phi\right) & =\int p\left(\mathbf{x}_{t+1} \mid \mathbf{y}_{1: t}, \phi\right) p\left(\mathbf{y}_{1: t} \mid \mathbf{x}_{t+1}, \phi\right) d \mathbf{x}_{t+1}
\end{aligned}
$$

Under the assumption that $G$ and $F$ in (24)-(25) are linear functions and the shocks are Gaussian, a closed-form solution to the filtering problem is yielded by the Kalman filter. In the presence of nonlinearities and deviations from Gaussianity, things become more complex and approximated solutions are needed. One possibility is to linearize the model by means of Taylor series expansions. This approach is sometimes referred to as the Extended Kalman Filter (Harvey (1990)). Conditions for convergence are often quite difficult to establish, however, and in what follows we will concentrate on a simulation-based approach to filtering which has the very useful feature to be extremely general.

The idea of a Sequential Monte Carlo filter - as anticipated - is to represent the distributions of interest (and therefore its moments and quantiles) by Monte Carlo approximations, namely by a set of $M$ particles. Let suppose to be at time $t-1$ and generate $M$ draws from

$$
p\left(\mathbf{x}_{t} \mid \mathbf{x}_{t-1}, \phi\right)
$$

thereby plainly simulating from the system of state equations. Next, let assign to each particle $m=1, \ldots, M$ a weight proportional to its likelihood:

$$
w_{t, m}=p\left(\mathbf{y}_{t} \mid \mathbf{x}_{t}, \phi\right) .
$$

Weights can be then normalized as:

$$
\tilde{w}_{t, m}=\frac{w_{t, m}}{\sum_{m=1}^{M} w_{t, m}},
$$

The weights can thus be used to compute Monte Carlo integrals via importance sampling.

It turns out that, after a certain number of steps, the filter might eventually degenerate, i.e. assign all the weight to a single particle - namely the one relatively most likely in view of the observed data. In order to avoid this, particles can be resampled: after having produced a set of particles and assigned to each one an appropriate weight, we associate to each particle $m$ a number of offspring $O_{m}$ such that $\sum_{m=1}^{M} O_{m}=M$. After this selection step, offspring particles 
replace the original particles and the importance weights are reset to $1 / M$, so that the set of particles can be thought of as a random sample. The resampling step can be implemented at every time interval (Gordon, Salmond and Smith, 1993), or it can be employed whenever the set of particles crosses a certain degeneracy threshold. A measure of degeneracy of the algorithm is the effective sample size (Liu and Chen, 1998), defined as:

$$
M_{e}=\frac{M}{1+\operatorname{Var}\left(w_{t}\right)} .
$$

This quantity can be estimated by:

$$
\hat{M}_{e}=\frac{1}{\sum_{m=1}^{M} \tilde{w}_{t, m}^{2}}
$$

when $\hat{M}_{e}$ drops below a certain threshold, the resampling takes place.

In our analysis, we compute the resampling in a computationally straightforward manner. Specifically, the number of offspring is taken to be proportional to the importance weight and generated via simulation of a set $U$ of $M$ uniformly distributed random variables on $[0,1]$, by using the cumulated sum of the normalized weights

$$
q_{m}=\sum_{j=1}^{m} \tilde{w}_{t, j}
$$

and then setting $O_{m}$ equal to the number of points in $U$ that fall between $q_{m-1}$ and $q_{m}$.

\subsection{Parameters Estimates}

It is also possible to employ a particle filter to perform parameter estimation. To do this, one can simply pretend that static parameters are indeed time-varying states, by adding a noise term at each time interval. The problem however is that, by doing so, relevant information is "thrown away" and additional variability generated. Liu and West (2001) propose a method to quantify such a loss of information, by allowing for an artificial parameter evolution scheme immune to this problem. Introducing artificial parameter evolution is equivalent to consider a model in which $\phi$ is replaced by its time-varying analog $\phi_{t}$, which evolves according to:

$$
\phi_{t}=\phi_{t-1}+\kappa_{t}, \quad \kappa_{t} \sim N\left(0, \xi_{t}\right)
$$

where $\xi_{t}$ is a diagonal matrix.

In a situation in which $\phi$ is fixed, the posterior distribution $p\left(\phi \mid \mathbf{y}_{1: t}\right)$ can be characterized by its Monte Carlo mean and variance $\bar{\phi}_{t}$ and $\mathbf{s}_{t}^{2}$, with $\mathbf{s}_{t}^{2}$ denoting the vector of empirical variances of each element in $\phi$. It is immediate to observe that, in the case of artificial parameter 
evolution, the Monte Carlo variance increases to $\mathbf{s}_{t}^{2}+\xi_{t}$. In fact, the Monte Carlo approximation can be expressed as kernel smoothed density of the particles as:

$$
p\left(\phi \mid \mathbf{y}_{1: t}\right) \approx \sum_{j=1}^{M} \kappa_{t}^{(j)} N\left(\phi_{t+1} \mid \phi_{t}^{(j)}, \xi_{t}\right)
$$

whereas the target variance $\mathbf{s}_{t}^{2}$ can be expressed as:

$$
\mathbf{s}_{t}^{2}=\mathbf{s}_{t-1}^{2}+\xi_{t}+2 \operatorname{Cov}\left(\phi_{t-1}, \kappa_{t}\right)
$$

By choosing

$$
\operatorname{Cov}\left(\phi_{t-1}, \kappa_{t}\right)=-\frac{\xi_{t}}{2}
$$

the loss of information can be easily avoided. A simple way to achieved this is to consider

$$
\xi_{t}=\mathbf{s}_{t}^{2}\left(\frac{1}{\delta}-1\right)
$$

where $\delta$ is a discount factor in $(0,1] .{ }^{17}$ If we define $d=\frac{3 \delta-1}{2 \delta}$, the conditional density evolution becomes:

$$
p\left(\phi_{t+1} \mid \phi_{t}\right) \sim N\left(\phi_{t+1} \mid d \phi_{t}+(1-d) \bar{\phi}_{t}, h^{2} s_{t}^{2}\right)
$$

where

$$
h^{2}=1-d^{2}=1-\left(\frac{3 \delta-1}{2 \delta}\right)^{2},
$$

so that sampling from (29) is equivalent to sampling from a kernel smoothed density in which the smoothing parameter $h$ is controlled via the discount factor $\delta$.

Clearly, the choice of the number of particles $M$ affects both the approximation of the prediction error distribution and the performance of the resampling algorithm. Our choice of 10,000 particles has been driven, on the one hand, by the need to have enough particles to capture the tails of $p\left(\phi \mid \mathbf{y}_{1: t}\right)$, on the other hand, by the evidence that - after a certain threshold - gains in noise reduction from the use of more particles become very small (Fernández-Villaverde and Rubio-Ramírez (2004b), Lombardi and Godsill (2005)).

To wrap up, all the necessary information about the state-space model parameters $\phi$ is summarized by the Monte Carlo approximation (28) of $p\left(\phi \mid \mathbf{y}_{1: t}\right)$, generated by $M$ particles. Each particle is hence mapped back into the parameter space of the structural model, enabling us to devise Monte Carlo approximations to the posterior probability distributions of the structural paramaters collected in $\theta$.

\footnotetext{
${ }^{17}$ Liu and West (2001) suggest to choose a value of $\delta$ around $0.95-0.99$.
} 


\subsection{Out-of-Sample Forecasts}

The sequential nature of the particle filter lends itself particularly well to perform out-of-sample forecasting of both state and observable variables. ${ }^{18}$ Indeed, the goal of the projection step is to construct random samples from the Monte Carlo approximation of the forecast distribution $\mathbf{x}_{t+1}$,computed using the posterior distribution of the state-space model parameters $\phi$, e.g.:

$$
p\left(\mathbf{x}_{t+1} \mid \mathbf{x}_{t}, \phi\right) .
$$

Each random sample $\mathbf{x}_{t+1}$ from the projected (or forecast) distribution is then turned into a random sample from the filtered distribution as weights are assigned and resampling is performed. In order to obtain multiple-step-ahead forecasts, it is therefore sufficient to keep projecting ahead the particles without any weighting or resampling. In this way, the Bayesian estimation methodology provides a useful tool for calculating the full probability distribution around the median (unconditional) forecast.

\section{Empirical Results}

\subsection{Structural Parameters: Posterior Distributions}

Table 2 summarizes end-of-sample information about the medians and the 95 percent probability intervals of the structural paramaters' posterior distributions under the two alternative monetary policy rules considered.

All in all, our results indicate that-under the assumption of fully rational expectations and serially uncorrelated disturbances-a substantial degree of structural rigidity has to be introduced in prototypical small-scale DSGE models to explain the amount of inertia in actual data. In particular, our estimates indicate that the degree of price stickiness, $\alpha$, and the degree of indexation to past inflation, $\gamma$, are unlikely to be lower than 0.94 , while the role of habit formation, $\eta$, is in the range $0.51-0.79$. Although inconsistent with microeconomic evidence on the importance of habit formation in consumption (Dynan (2000)) and on price setting behavior (Bils and Klenow (2004)), such high degrees of structural persistence appear comparable with those found in other papers drawing on similar neo-Keynesian models estimated on detrended data. $^{19}$

\footnotetext{
${ }^{18}$ Please note that whenever we refer to the out-of-sample performance of our DSGE model, we always consider the state-space representation of the DSGE model, and not its VAR approximation.

${ }^{19}$ For instance, Rotemberg and Woodford (1997) and Giannoni and Woodford (2003) using a similar model estimate $\gamma=1$ and $\eta=1$, while fixing $\alpha=.66$. Christiano et al. (2004) and Altig et al. (2005) estimate $\eta$ to
} 
In line with previous empirical studies, shocks to productivity growth are also found to be highly correlated-with serial correlation, $\vartheta$, unlikely to be lower than 0.91 -while estimates of the monetary policy reaction function point to a sizable degree of interest rate smoothing ( $\rho$ is ranging between 0.80 and 0.89 ), a high responsivenness to inflation ( $\varphi_{1}$ is over 1.58) and a sizable degree of activism $\left(\varphi_{2}\right.$ is over 0.63$)$. The aggregate expenditure's elasticity of intertemporal substitution, $\sigma^{-1}$, is estimated to be significantly below 1 , implying a coefficient of risk aversion between 1.29 and 2.06-a result which is also quite common in the literature. Perhaps more interestingly, the equilibrium rate of the economy, $g^{*}$, is estimated to be lower than 2.7 percent per annum at the end of the sample, whereas the posterior distributions of $p_{u}$ and $p_{d}$ show that changes in the steady-state rate of inflation occur frequently, with-on average-a 15 percent higher probability of downward over upward revisions.

Our estimates also allow to characterize the structure of the economy which is most likely to be associated with a certain monetary policy rule, given the inherent uncertainty about structural parameters and shock processes governing the evolution of the economy under equilibrium conditions. As to be hoped in the context of a structural rational-expectations model, estimates of the deep parameters are broadly invariant to the policy rule specification: overall, the magnitude of the changes in posterior means and probability intervals is small and statistically insignificant. Interestingly, though, an output gap rule is likely to feature a higher degree of activism, $\varphi_{2}$, a stronger response to inflation, $\varphi_{1}$, and-if anything-a little more inertia, $\rho$, than its output growth counterpart, while facing substantially greater uncertainty about the steady-state growth rate of the economy, $g^{*}$. Tellingly, under an output gap rule, the 95 percent probability interval of $g^{*}$ posterior distribution is estimated to be positively skewed and $2 \frac{1}{2}$ times as large as under an output growth rule.

The use of a sequential estimation technique is also helpful to track down time variation in the distribution of policy and structural parameters, as well as instability in error variances. In this respect, Figure 1 plots the evolution over the whole sample of the estimated policy response to inflation and output, the smoothing parameter, the probability of revising up and down the inflation target, as well as the standard deviation of monetary shocks, $\sigma_{\zeta^{r}}$, under the two monetary rules considered. Quantitatively, shifts in the corresponding posterior medians seem be .65 and $\alpha=.82$, while fixing $\gamma=1$. Under rational expectations, Milani (2005) obtains $\gamma=.89, \eta=.91$, and $\alpha=.92$. Smets and Wouters (2004) estimate $\gamma=.66, \eta=.69$, and $\alpha=.87$ on a 1974-2002 sample. Their estimates are somewhat lower than other papers, but still surprisingly large if we consider that they are obtained in a rich model, incorporating, besides habits, sticky prices, and indexation, also wage stickiness, capital formation, adjustment costs, and several highly autocorrelated shocks. 
to be limited under both policy reaction functions, offering scarce support to the conventional wisdom about the loss of monetary control in the 1970s and its subsequent reemergence ${ }^{20}$. However, systematic monetary policy responses appear less stable under an output gap rule than under an output growth rule. Indeed, the feedback coefficients of the growth rule are broadly constant over the sample, if we except a drastic one-off increase in the output response over the second half of the 1970s. In contrast, under a gap rule specification, the inflation response is likely to have fallen at the beginning of the 1970s, to have recovered in the mid 1970s, and to have steadily increased from the early-1980s onwards. Similarly, the output response appears to have risen quickly over the second half of the 1970s and to have stabilized at such a higher level since the early 1980s. Interestingly though, a growth rule features a higher degree of time variation in the unsystematic part of monetary policy than a gap rule. Indeed, while the volatility of monetary shocks appears to be roughly constant under the output gap rule, it looks hump-shaped under the growth rule, with a peak at the turn of the 1980s-the time of the Volker experiment.

Time variation in medians and probability intervals of the structural paramaters' posterior distributions can be observed in Figure 2. In this respect, results are less clear-cut. On the one hand, pricing parameters are essentially time-invariant once shifts in trend growth and inflation are accounted for. Equally, the decline in the size of supply shocks is found to be small and statistically insignificant. On the other hand, both volatility of intertemporal preference shocks and elasticity of intertemporal substitution are likely to have fallen significantly over time, while the role of habit formation and shocks to trend productivity have somehow become larger. Our findings seem hence to support Cogley and Sbordone's (2005) argument that allowing for heteroskedasticity and time variation in the underlying stochastic processes governing the evolution of an economy under flexible prices permits to validate a structural, constant-parameter, neo-Keynesian model of price adjustments. We are, however, unable to extend the same argument to a structural, neo-Keynesian model of adjustments in aggregate expenditure. Conceivably, distinguishing the evolution of private investment from private and public consumption might be enlightening in this respect.

\footnotetext{
${ }^{20}$ Several papers-among which Taylor (1999) and Clarida, Galí, and Gertler (2000)-find that during the great inflation period the U.S. Federal Reserve pursued a policy that accommodated inflation and induced instability in the economy, by lowering real interest rates when expected inflation increased and viceversa. These studies suggest that this perverse practice ended with Paul Volker's appointment, when the policy response to expected inflation became "sufficiently" aggressive to restore monetary stability.
} 


\subsection{Unobservable State Variables: A Real-Time Policy Assessment}

Let us now turn the attention to the main policy questions raised at the outset. Has the Fed over 2001-03 cut interest rates by "too much" in relation to the expected return on capital? Have the latest Fed's rate hikes completely removed policy accomodation, thereby allowing the real Fed fund rate to rise again to the NRI? The answers are to be found in Figure 3. Specifically, drawing on our "neo-Wicksellian" framework embedding an output growth monetary policy rule, Figure 3 tracks down in real time the median and the 95 percent probability intervals of the implied distributions of NRi (top panel), output gap (second panel), trend growth (third panel) and equilibrium inflation (bottom panel) vis-á-vis their actual values, whenever they exist.

According to the gap between the actual real rate of interest and our real-time measure of the NRI taking into account filter uncertainty, the Fed-to deal with the economic downturn following the stockmarket crash - has been cutting interest rates aggressively, thereby driving the cost of capital significantly below the NRI for over four years-from 2001Q3 to 2005 Q3. Over the most recent quarters, however, repeated monetary policy tightening has managed to fully correct the disequilibrium, while slowing down growth and realigning real output with its estimated potential level. At the end of the sample, the posterior median of the NRI is estimated at 2.9 percent, with a 95 probability interval ranging from 2.1 to 3.7 percent. At the same time, the posterior median of the trend growth rate is estimated at $3 \frac{1}{2}$ percent, with a 95 percent probability interval ranging from 2.3 to 5.2 percent. Actual growth appears to be below such a trend, as the output gap is closing, in line with recent indications that a slowdown is currently underway in the U.S. economy. Yet, core inflation appears to have creeped up since 2004, and is estimated to have risen slightly above its target during the last year.

Using the same benchmark for a retrospective assessment, it appears that U.S. monetary policy has been "significantly loose" in other four episodes: during the five years running between 1974Q4 and 1979Q3-when the real interest rate has reached a record-low of 650 basis points beneath its "appropriate level"-and, more briefly, over the late 1960s, in 1970-71 and in 1991-94. In all these events, the negative real interest rate gap has been preceeded by episodes of slowdown in trend productivity growth and associated with episodes of rising inflation target. Low-frequency fluctuations in potential output growth are tracable in the third panel of Figure 3. Their suitability is indirectly validated by panel two, where resulting troughs denoting the end of periods of economic contraction in 1970Q1, 1975Q1, 1991Q1, and 2001Q4 nicely match available evidence about NBER's dating of the US business cycle. The estimates of 
the Federal Reserve's inflation target-shown in the bottom panel of Figure 3-suggest that the Fed's inflation target rose from about $1 \frac{3}{4}$ percent in 1958 to a peak of $6 \frac{1}{2}$ percent in 1980 before falling back below 2 percent by the end of the sample period in $2006 .^{21}$

Granger causality tests reported in Table 3 appears to validate a "chain of events" running from productivity shocks to the Fed's policy stance. Based on vector autoregressive models allowing for 1, 2, 3, and 4 lags, results indicate that changes in the inflation target are Granger caused by changes in trend productivity growth. Noticeably, there is no feedback running in the opposite direction in the first two quarters. Shifts in target (e.g. long-run) inflation, in turn, appear to Granger cause changes in the real interest rate gap, while reverse causality kicks in from the second quarter onwards. These supplemental findings strengthen the belief that-to a large extent-the loss of monetary control over the 1970s could be ascribed to initial central banks' inability to disentangle permanent from transitory shifts in productivity. By relying on flawed measures of potential output, Federal Reserve policy has had an inclination to overestimate the slack in the economy whenever trend growth has slowed down, and viceversa. ${ }^{22}$ This interpretation of the Great Inflation ties in well with previous evidence of a drastic oneoff increase in the monetary response to output over the mid-1970s and is not completely at odds with views attributing the rise in U.S. inflation during the 1960s and 1970s to a systematic tendency of Fed's policy to translate adverse supply-side shocks into more persistent movements in the inflation rate itself. ${ }^{23}$ This is quite interesting, given that such causal links are by no means implied by our structural model. Implicit in our framework are the negative relationship between the real interest rate and the output gap and the positive relationship between the interest rate and the inflation gap, whereas the evolution of trend productivity growth and long-run inflation (e.g. the inflation target) are, by construction, exogenous and mutually independent. The results are instead related to the fact that real-time estimates per se have a tendency to overemphasize the magnitude of slackness (inflationary pressures) in the

\footnotetext{
${ }^{21}$ Interestingly, our implied Fed inflation target turns up to be very close to the one recently estimated by Ireland (2007), who draws on real-time Kalman filter estimates of a slightly more complex neo-Keynesian model of the US economy.

${ }^{22}$ Indeed, by estimating monetary reaction functions using measures of the output gap and future inflation available to policy makers in "real time", Orphanides (1998 and 2002) and McCallum (2001) suggest that it was flaws in the data rather than inattention to inflation that led the Federal Reserve to stimulate demand excessively.

${ }^{23}$ See, among others, Blinder (1982) and Mayer (1998). Symmetrically, this may suggest that, since 1980, the Fed has acted "opportunistically" to bring inflation back down in the aftermath of more favorable supply-side disturbances (Bomfim and Rudebusch (2000) and Orphanides and Wilcox's (2002)).
} 
economy during periods of decelerating (accelerating) trend productivity growth. This stems from inherent lags in the update of trend growth estimates based on available information, following unexpected shifts to the underlying rate of productivity. Since, in reality, sizable transitory fluctuations in productivity are likely to obscure agents' view of the underlying trend growth rate, incorporating such updating/revision process improves the model's ability to generate responses to productivity shifts that resemble historical experience, by giving rise to persistent forecast errors. $^{24}$

How do our estimates compare with other empirical measures for the United States? Figure 4 plots posterior medians of the unobservable state variables estimated using our benchmark model (e.g. embedding an output growth rule) with those obtained using the same model under an output gap rule. Interestingly, under the latter specification, the equilibrium rate of inflation is found to be persistently lower (and the NRI just a little lower) after the 1980sa result which is not surprising given the higher responsiveness to inflation and the higher probability of revising down the target characterizing the output gap rule over this period. Respective output gap and trend growth estimates are almost undistinguishable over the whole sample, with the exception of the late 1970s, when trend growth appears to be higher under a growth rule specification. We also juxtapose our real-time measures with Laubach and Williams' (2003) Kalman filter estimates based on a backward-looking unobserved component model encompassing a Phillips curve and an aggregate demand equation. Despite the similar amplitude of fluctuations over the second half of the sample, Laubach and Williams' measure of NRI exhibits a downward trend before the 1980s. Structural restrictions link NRI movements with those in the rate of productivity growth. By construction, the latter are stationary in our model, while they are assumed to follow an I(1) process in Laubach and Williams' framework. A comparison with standard univariate Hodrick-Prescott filters (having a smoothing parameter of 1600 for quarterly data) is also presented in Figure 4. The resulting output gap measure looks remarkably close to the one implied by our model. Nonetheless, it is quite obvious that while the HP filter simply tracks the trend in each observed variable, our estimates also take into account information contained in their structural macroeconomic interactions.

\subsection{Out-of-Sample Forecasts and Model Evaluation}

To assess the time series fit of our estimated neo-Keynesian model, posterior predictive checks are summarized in Figure $6 .{ }^{25}$ Specifically, red dotted lines in the first row of charts plot 5-year

\footnotetext{
${ }^{24}$ See, for instance, Lansing (2000), Roberts (2001), and Edge, Laubach and Williams (2004).

${ }^{25}$ The notion of Bayesian posterior predictive checks is explained in details in Geweke (2005).
} 
moving averages of the predictive posterior medians of the three observable variables $r, y, \pi$, respectively. 5-year moving averages of their first-order autoregressive coefficients and standard deviations are similarly illustrated in the second and third row of charts. Black solid lines in each of the 9 graphs denote corresponding sample statistics. If the estimated model fits well and is able to explain the salient features of the data, the statistics obtained using sample moments should overlap those obtained using information from the posterior predictive distribution of the relevant observable variable. ${ }^{26}$ In this perspective, Figure 2 highlights several important points.

The in-sample fit of the model (first row of charts) is fairly good, as there seems to be no major discrepancy between actual and predicted values. Over the whole sample, Root Mean Squared Errors of the one-step-ahed forecasts for $r(0.61), y(1.17)$, and $\pi(0.27)$ are somewhat larger than those resulting from other DSGE models, but comparable with those from standard VAR models (see, for instance, Smets and Wouters, 2007), meaning that the advantage of tracking down the evolution of underlying stochastic processes did not come at the expense of markedly worse predictive performance. Yet, accounting for the real-time evolution of underlying trends in macroeconomic variables seems quite effective in matching the degree of inertia found in actual data. ${ }^{27}$ Absent this mechanism, it would be unthinkable that-under assumptions of rational expectations and white noise disturbances-our prototypical model could endogenously reproduce the amount of persistence inherent in the series, no matter how high the degree of habit formation and backward-lookingness incorporated in the adjustment process. Nonetheless, the model exhibits a general tendency to underpredict interest rate volatility. This is likely to stem from the absence of risk premia in a framework assuming friction-free financial markets and no term structure.

Turning to the out-of-sample performance of our model, Figure 7 extends the information reported in Figure 3 over the 12-quarter forecasting horizon 2007Q1-2009Q4. Specifically, the chart presents, in black, median and 95 percent probability intervals of the out-of-sample posterior predictive distributions for the NRI (top panel), output gap (second panel), trend growth (third panel) and equilibrium inflation (bottom panel), vis-á-vis median projections of their corresponding observable values, namely the real interest rate, the annualized growth rate, and the inflation rate. As explained in Section 3.3, out-of-sample median forecasts for

\footnotetext{
${ }^{26}$ Given the similarity of the results, posterior predictive checks are reported only for the benchmark model embedding a monetary policy rule responding to output growth. For the alternative interest rate rule specification, results are nonetheless available upon request.

${ }^{27}$ On this point, see also Chang, Doh, and Schorfheide (2006) and Laubach and Williams (2005a).
} 
the observable variables $r, y$, and $\pi$ are obtained by projecting $1,2, \ldots, 12$ periods ahead the particles, on the basis of the estimated posterior distributions of parameters and unobservable state variables available at the end of the sample. In this context, it is worth recalling that we are here dealing with unconditional forecasts and forecast ranges. That is, implicit in our out-of-sample forecast distributions is the assumption that the Fed will keep correcting for deviations of target variables from equilibrium, by adjusting the policy rate in line with the estimated policy rule (although with some typical errors). As a consequence, the reported out-of-sample median forecasts can be deemed as representing the most likely transition path back to its stochastic equilibrium, given available information at the end of the sample. Such available information relates to our updated inference about (i) the structure of the economy (in terms of parameters and underlying trends), (ii) the volatility of the shocks, and (iii) policy preferences. In this respect, model forecasts are provided under an interest rate rule responding to output growth (left column) as well as for an alternative output gap rule specification (right column). Consistently with what observed in section 4.1. and 4.2, both model specifications imply that-at the end of 2006-inflation is slightly (though not significantly) above target while real output is broadly in line with potential. The divergent interest rate paths projected under the two model specifications are due to the fact that the inflation target (and marginally also the NRI) is estimated to be lower under an output gap rule than under an output growth rule. Conditional upon a larger inflation gap, a stronger inflation response, and a zero output gap at the beginning of the forecasting horizon, the policy rule responding to the output gap implies a (significantly) restrictive policy stance moving forwards. In contrast, the rule reacting to deviations of output growth from equilibrium calls for an accomodative monetary stance by the end of the horizon,.as adverse pseudo-random shocks are expected to hit the underlying rate of productivity over the next 3 years.

What can we say about the uncertainty surrounding projected interest rate settings? What is the relative precision of our interest rate gap measure over the next 12 quarters under the two rules? Figure 8 plots-for each model specification considered-the degree of uncertainty surrounding respective interest rate gap central forecasts (black dotted lines). The Figure also shows counterfactual forecast ranges (in solid red lines) were model parameters (top panels) or unobservable state variables (bottom panels) assumed to be known with certainty at the beginning of the forecast horizon. Overall, the amplitude of the forecasting ranges is broadly the same under the two rules. Specifically, under a growth rule, the 95 percent probability interval widens from $-\frac{1}{2}$ to +1 percent after 1 quarter to $-3 \frac{1}{2}$ to +1 percent after 3 years; under an output gap rule, the forecast bounds range from $+\frac{1}{2}$ to +2 percent after 1 quarter, and 
from -1 to $+3 \frac{1}{2}$ percent after 3 years. Equally, under both specifications, uncertainty about future interest rate setting mainly stems from uncertainty about inference of the underlying equilibrium position. Specifically, under a growth rule, assuming full knowledge of the initial state of the economy artificially reduces forecasting ranges to just 0.6 percent over the whole forecasting horizon. Under a gap rule, the gain is slightly less (0.7 percent after 1 quarter and $1 \frac{1}{2}$ percent at the end of the forecast horizon). What truly differs under the two rules is the degree of imprecision surrounding the steady-state growth rate of the economy, $g^{*}$. The higher fuzziness around the parameter $g^{*}$ characterizing the output gap rule specification translates into greater uncertainty about future monetary policy stance only if uncertainty about the initial state of the economy is neglected. Taking this into account makes clear that different feedback rule specifications imply different monetary policy stances in the future, but not different degrees of uncertainty around it. Indeed, the lower inflation target, the tougher responses to disequilibria, the slightly higher inertia, and the greater degree of fine tuningwhich are likely to be associated with an output gap rule-can be seen as forms of insurance against its inherently higher uncertainty about $g^{*}$. By keeping its eye fixed on the ball, such a policy automatically counteracts the unavoidable policy "mistakes" resulting from equilibrium mismeasurement.

\section{Conclusions and Prospects}

From a normative perspective, this paper investigates the policy implications of relying on unrealistic modeling assumptions and ignoring key issues-such as the quantitative determination of equilibrium values in real time. In this respect, two lessons can be drawn from our analysis. Lesson one: the importance of accounting for imperfect knowledge about the (permanent or cyclical) nature of a shock. DSGE models tend to assume that agents immediately recognise the nature of a shock to productivity and modify their expectations accordingly. However, in practice, sizable transitory fluctuations in productivity are likely to obscure agents' and policymakers' view of the underlying trend growth rate. Our results demonstrate how real-time expectations have a tendency to overemphasize the magnitude of slackness (inflationary pressures) in the economy during periods of decelerating (accelerating) trend productivity growth. The persistence of forecast errors relates to inherent lags in learning about shifts in the underlying rate of productivity, given available information. Incorporating this expectation revision process is found to improve substantially models' ability to generate responses to productivity shifts that resemble historical experience, by giving rise to serially correlated forecast errors. 
Lesson two: the importance of accounting for time variation in the underlying evolution of the economy. According to our estimates, more than 85 percent of the uncertainty about future interest rate settings is due to vagueness in the estimate of today's equilibrium, rather than to imprecision about the structural parameterization of the model economy or the policy rule. Structural models ignoring time variation in underlying trends are hence extremely unlikely to help policymaking in providing guidance to the markets as to how they will respond to ongoing economic developments.

From a positive perspective, this paper is an original attempt to provide real-time policy assessment using a structural neo-Keynesian model, which ensures consistency between the specification of price adjustments and the evolution of the economy under flexible prices and is generalized to allow for nonstationarity in the underlying stochastic processes. Accounting for the real-time evolution of underlying trends in productivity and real output seems capable of matching the empirical properties of macroeconomic data, thus having the potential for improving fit and forecasting performance of rational-expectation monetary models.

To fit our dynamic optimizing model to the data, its likelihood function is evaluated using a Sequential Monte Carlo algorithm providing joint inference about structural parameters and unobservable, nonstationary state variables. To our knowledge, this is a very innovative way to bring DSGE models to data. Up to now, particle filters have been used to reconstruct the likelihood of these models, but not to perform parameter estimation. We propose an indirect way of proceeding, yielding parameter estimates directly from the filtering procedure through a single solution of the model for each particle, thereby drastically reducing the computational burden otherwise needed to solve the model for each particle and for each time stamp. Importantly, the paper illustrates how the posterior distribution of the model can be used to carry out predictive checks, to test for parameter instability, to construct forecast ranges, and to disentangle parameter from state uncertainty in associated forecast errors.

Despite these important contributions, this paper fails to exploit the full potential of the particle filtering methodology. Indeed, while our analysis is based on a linearized version of the model, work is ongoing to incorporate nonlinearities and nongaussian volatilities. This would require the use of higher order refinement for the solution of the rational expectation systeman area where research is very active at the moment. In addition, the identification of the deep parameters would call for nonlinear mapping from the structural neo-Keynesian model into its state-space representation, another big challenge the literature on DSGE models needs to cope with (Beyer and Farmer, 2004; Canova and Sala, 2005). Finally-given the inherent resemblance between the simulation-based updating scheme adopted in this paper and the 
"learning mechanism" of agents' beliefs-future studies may well attempt to relax the current assumption of rational expectations and bring in learning dynamics. Presumably, introducing sluggish expectation adjustments alongside real-time estimates of underlying trends might help discriminate between competing views of the data, understand more fully the policy mistakes of the past, and guard more reliably against similar mistakes in the future (Bayoumi and Sgherri (2004) and Milani (2005)). 


\section{References}

[1] Altig, D., Christiano, L.J., Eichenbaum, M., and J. Linde (2002) "Technology Shocks and Aggregate Fluctuations", unpublished manuscript, Northwestern University.

[2] Amisano, G., and O. Tristani, (2006) "Euro area inflation persistence in an estimated nonlinear DSGE model," unpublished manuscript, University of Brescia and European Central Bank.

[3] An, S., and F. Schorfheide, (2005) "Bayesian Analysis of DSGE Models," CEPR Discussion Paper No. 5207.

[4] Andrés, J., López-Salido, J.D., and E. Nelson (2004) "Money and the Natural Rate of Interest: Estimates for the U.K., the U.S., and the Euro Area." CEPR Discussion Paper No. 4337 .

$[5]$ (2005) "Sticky-Price Models and the Natural Rate Hypothesis," Working Paper Series 2005-18, Federal Reserve Bank of St. Louis.

[6] Ascari, G., (2004) "Staggered Prices and Trend Inflation: Some Nuisances", Review of Economic Dynamics, Vol. 7, pp. 642-67.

[7] Basdevant, O., Björksten N., and O. Karagedikli, (2004) "Estimating a time varying neutral real interest rate for New Zealand ", Reserve Bank of New Zealand Discussion Paper, DP2004/01.

[8] Bayoumi, T., and S. Sgherri, (2004) "Monetary Magic? How the Fed Improved the Flexibility of the Economy," CEPR Discussion Paper No. 4696.

[9] Benati, L., (2004) "Monetary Rules, Indeterminacy, and the Business-Cycle Stylised Facts," unpublished manuscript, Bank of England.

[10] Beyer, A., and R. Farmer, (2004) "On the Indeterminacy of New Keynesian Economics," ECB Working Paper No. 323.

[11] Bils, M., and Klenow, P., (2004) "Some Evidence on the Importance of Sticky Prices," Journal of Political Economy, Vol. 112, pp. 947-85.

[12] Blanchard, O., and C. Kahn, (1980) "The Solution of Linear Difference Models under Rational Expectations," Econometrica, Vol. 48, pp. 1305-11. 
[13] Boivin, J., and M. Giannoni, (2003) "Has Monetary Policy Become More Effective?", NBER Working Paper no. 9459, National Bureau of Economic Research, Inc.

[14] Calvo, G.A. (1983). "Staggered Prices in a Utility-Maximizing Framework," Journal of Monetary Economics, Vol. 12, pp. 383-98.

[15] Canova, F., M. Finn, and A. Pagan (1994) "Evaluating a Real Business Cycle Model," in: C. Hargreaves (ed.) Non-stationary Time Series Analysis and Cointegration,

[16] Canova, F., and L. Sala, (2005) "Back to Square One: Identification Issues in DSGE Models," ECB Working Paper No. 583.

[17] Chang, Y., Doh, T., and F. Schorfheide, (2006) "Non-stationary Hours in a DSGE Model", Journal of Money, Credit, and Banking, forthcoming.

[18] Christiano, L., (2002) "Solving Dynamic Equilibrium Models by a Method of Undetermined Coefficients," Computational Economics, Vol. 20, pp. 21-55.

[19] Christiano, L.J., Eichenbaum, M., and C.L. Evans, (2005). "Nominal Rigidities and the Dynamic Effects of a Shock to Monetary Policy", Journal of Political Economy, Vol. 113 (1), pp. $1-45$.

[20] Clarida, R., Galí, J., and M. Gertler, (2000) "Monetary Policy Rules and Macroeconomic Stability: Evidence and Some Theory," Journal of Political Economy, Vol. 115, pp. 147-80.

[21] Cuaresma, J.C., Gnan, E . and D. Ritzberger-Grunenwald, (2004) "Searching for a natural rate of interest: a euro area perspective", Empirica, Vol 31, pp. 185-204.

[22] Del Negro, M., Schorfheide, F., Smets, F., and R. Wouters, (2004) "On the Fit and Forecasting Performance of New Keynesian Models" Federal Reserve of Atlanta, Working Paper 2004-37.

[23] Doucet, A., Godsill, S., and C. Andrieu, (2000) "On sequential Monte Carlo sampling methods for Bayesian Fltering," Statistics and Computing, Vol. 10, pp. 197-208.

[24] Fernández-Villaverde, J., and J. Rubio-Ramírez, (2004a) "Comparing Dynamic Equilibrium Models to Data: a Bayesian Approach," Journal of Econometrics, Vol. 123, pp. $153-87$.

$[25]$ (2004b) "Estimating Macroeconomic Models: A Likelihood Approach," Manuscript, University of Pennsylvania. 
[26] Galí, J., López-Salido, J.D., and J. Vallés, (2003). "Technology Shocks and Monetary Policy: Evaluating the Fed's Performance," Journal of Monetary Economics, Vol. 50, pp. $723-43$.

[27] Garnier, J., and B. R. Wilhelmsen, (2005) "The Natural Real Interest Rate and The Output Gap in the Euro Area: A Joint Estimation," ECB Working Paper No. 546.

[28] Giammarioli, N., and N. Valla, (2003), "The Natural Rate of Interest in the Euro area", ECB Working Paper No. 233.

[29] Giannoni, M., and M. Woodford, (2005). "Optimal Inflation Targeting Rules", in B.S. Bernanke and M. Woodford, eds., The Inflation-Targeting Debate, Chicago: University of Chicago Press.

[30] Gordon, N., Salmond, D., and A. Smith, (1993) "Novel Approach to Nonlinear/NonGaussian Bayesian State Estimation," IEEE Proceedings-F, Vol. 140, pp. 107-13.

[31] Harvey, A.C., (1990) Structural Time Series Model and the Kalman Filter, Cambridge: Cambridge University Press.

[32] Ireland, P. (2007) "Changes in the Federal Reserve's Inflation Target: Causes and Consequences," Journal of Money, Credit, and Banking, forthcoming.

[33] Kim, S., Shephard, N., and S. Chib, (1998) "Stochastic Volatility: Likelihood Inference and Comparison with ARCH models," Review of Economic Studies, Vol. 65, pp. 361-93.

[34] Kitagawa, G., (1996) "Monte Carlo Filter and Smoother for Non-Gaussian Nonlinear State-Space Models," Journal of Computational and Graphical Statistics, Vol. 5, pp. 1-25.

[35] Klein, P., (2000) "Using the Generalized Schur Form to Solve a Multivariate Linear Rational Expectations Model," Journal of Economic Dynamics and Control, Vol. 24, pp. 1405-23.

[36] Klein, P., (2005) "Second-order approximation of dynamic models without the use of tensors," unpublished manuscript, University of Western Ontario.

[37] Laubach, T., (2001) "Measuring the NAIRU: Evidence from Seven Economies," The Review of Economics and Statistics, Vol. 83(2), pp. 218-31.

[38] Laubach, T., and J. C. Williams, (2003) "Measuring The Natural Rate Of Interest," The Review of Economics and Statistics, Vol. 85(4), pp. 1063-70. 
[39] , (2003) "Imperfect Knowledge, Inflation Expectations, and Monetary Policy," NBER Working Papers No. 9884.

[40] — (2005a) "Monetary policy with imperfect knowledge," Working Papers in Applied Economic Theory 2005-17, Federal Reserve Bank of San Francisco.

[41] , (2005b) "The Decline of Activist Stabilization Policy: Natural Rate Misperceptions, Learning and Expectations," CEPR Discussion Papers No. 4865.

[42] Levin, A.T., Onatski, A., Williams J. C., and N. Williams, (2005) "Monetary Policy Under Uncertainty in Micro-Founded Macroeconometric Models," NBER Working Papers No. 11523 .

[43] Liu, J., and R. Chen, (1998) "Sequential Monte Carlo methods for dynamic systems," Journal of the American Statistical Association, vol. 93, pp. 1032-44.

[44] Liu, J., and M. West, (2001) "Combined parameter and state estimation in simulationbased fltering," in Sequential Monte Carlo Methods in Practice, A. Doucet, J. de Freitas, and N. Gordon, eds. Springer-Verlag, New York.

[45] Lombardi, M.J., and Godsill, (2005) "On-line Bayesian estimation of AR signals in symmetric alpha-stable noise," IEEE Transactions on Signal Processing, Vol. 53, pp. 1-6.

[46] Lubik, T. A., and Surico, P. (2006) "The Lucas Critique and the Stability of Empirical Models," Federal Reserve Bank of Richmond Working Paper No. 06-05.

[47] McCallum, B.T., (1998). "Stickiness: A Comment", Carnegie-Rochester Conference Series on Public Policy, Vol. 48, pp. 357-63.

[48] McCallum, B.T., and E. Nelson, (1999). "Performance of Operational Policy Rules in an Estimated Semi-Classical Structural Model", in Monetary Policy Rules, J.B. Taylor, ed., University of Chicago Press.

[49] Mésonnier, J.-S, and J.-P. Renne, (2006) "A Time-Varying Natural Rate of Interest for the euro area", European Economic Review, forthcoming.

[50] Milani, F., (2004). "Adaptive Learning and Inflation Persistence", unpublished manuscript, Princeton University.

[51] Neiss, K. and E. Nelson, (2003) "The real rate gap as an Inflation Indicator ", Macroeconomic Dynamics, Vol. 7, pp. 239 -62. 
[52] Orphanides, A., and J. C. Williams, (2006) "Inflation targeting under imperfect knowledge," Working Paper Series 2006-14, Federal Reserve Bank of San Francisco.

[53] Pitt, M., and N. Shephard, (1999) "Filtering via Simulation: Auxiliary Particle Filters," Journal of the American Statistical Association, Vol. 94, pp. 590-599.

[54] Rotemberg, J.J. and M. Woodford (1999). "Interest-Rate Rules in an Estimated StickyPrice Model", in Monetary Policy Rules, John B. Taylor, ed., University of Chicago Press.

[55] Schmitt-Grohe, S., and M. Uribe, (2004) "Solving Dynamic General Equilibrium Models Using a Second-Order Approximation to the Policy Function," Journal of Economic Dynamics and Control, Vol. 28, pp. 755-75.

[56] Sevillano, J. M. M. and M. M. Simon, (2004) "An empirical approximation of the natural rate of interest and potential growth", Working paper No 0416, Banco de Espana.

[57] Sims, C., (2002) "Solving Linear Rational Expectations Models," Computational Economics, Vol. 20, pp. 1-20.

[58] Sims, C.A., and T. Zha, (2004) "Were There Regime Switches in US Monetary Policy?", Working Paper 2004-14, Federal Reserve Bank of Atlanta.

[59] Smets, F., and R. Wouters, (2003) "Monetary Policy in an Estimated Stochastic Dynamic General Equilibrium Model of the Euro Area", Journal of the European Economic Association, Vol. 1(5), pp. 1123-75.

[60] _ (2004) "Forecasting with a Bayesian DSGE Model: An Application to the Euro Area", Journal of Common Market Studies, Vol. 42(4), pp 841-867.

[61] _ (2005) "Comparing Shocks and Frictions in US and Euro Area Business Cycle", Journal of Applied Econometrics, vol. 20(2), pp. 161-183.

[62] Smith, A., (1993) "Estimating Nonlinear Time-Series Models Using Simulated Vector Autoregressions," Journal of Applied Econometrics, Vol. 8, pp. S63-S84.

[63] Uhlig, H., (1999) "A Toolkit for Analyzing Nonlinear Dynamic Stochastic Models Easily" in Ramon Marimom and Adrian Scott (eds.) Computational Methods for the Study of Dynamic Economies, Oxford University Press.

[64] Woodford, M., (2003) Interest and Prices: Foundations of a Theory of Monetary Policy, Princeton University Press. 
Table 1: Prior distribution of static parameters

\begin{tabular}{|c|c|c|c|c|c|}
\hline \multirow[b]{2}{*}{ Description } & \multirow[b]{2}{*}{ Par. } & \multicolumn{4}{|c|}{ Prior Distribution } \\
\hline & & Density & Domain & Mean & Std. Dev. \\
\hline Degree habit formation & $\eta$ & Beta & {$[0,1)$} & .5 & .3 \\
\hline Intertemp. elast. substitution & $\sigma^{-1}$ & Gamma & $\mathbb{R}^{+}$ & .4 & .2 \\
\hline Subjective discount factor & $\beta$ & Beta & {$[0,1)$} & .995 & .0025 \\
\hline Degree inflation indexation & $\gamma$ & Beta & {$[0,1)$} & .9 & .05 \\
\hline Fraction non-optim. firms & $\alpha$ & Beta & {$[0,1)$} & .2 & .1 \\
\hline Steady-state growth rate & $10^{2} \cdot g^{*}$ & Normal & $\mathbb{R}$ & .75 & .1 \\
\hline Autocorr. product. growth & $\vartheta$ & Beta & {$[0,1)$} & .8 & .3 \\
\hline Interest rate smoothing & $\rho$ & Beta & {$[0,1)$} & .8 & .2 \\
\hline Feedback on inflation & $\varphi_{1}$ & Normal & $\mathbb{R}$ & 1.5 & .3 \\
\hline Feedback on output gap & $\varphi_{2}$ & Normal & $\mathbb{R}$ & .5 & .2 \\
\hline Inflation target: prob_up & $p_{u}$ & Beta & {$[0,1)$} & .25 & .075 \\
\hline Inflation target: prob_down & $p_{d}$ & Beta & {$[0,1)$} & .25 & .075 \\
\hline Drift prod. shock: std. dev. & $10^{2} \cdot \sigma_{\zeta^{g}}$ & Lognor. & $\mathbb{R}^{+}$ & .075 & .075 \\
\hline Level prod. shock: std. dev. & $10^{2} \cdot \sigma_{\zeta^{z}}$ & Lognor. & $\mathbb{R}^{+}$ & .25 & .25 \\
\hline Prefer. shock: std. dev. & $10^{2} \cdot \sigma_{\zeta^{u}}$ & Lognor. & $\mathbb{R}^{+}$ & 1.5 & 1.5 \\
\hline Supply shock: std. dev. & $\sigma_{\zeta^{\pi}}$ & Lognor. & $\mathbb{R}^{+}$ & 1.14 & .03 \\
\hline Monetary shock: std. dev. & $\sigma_{\zeta^{r}}$ & Lognor. & $\mathbb{R}^{+}$ & 1.16 & .02 \\
\hline
\end{tabular}


Table 2: Posterior distributions of static parameters in 2006Q4

\begin{tabular}{cccccc}
\hline \hline & & \multicolumn{2}{c}{ Growth rule } & \multicolumn{2}{c}{ Gap rule } \\
\hline Description & Par. & Median & $95 \%$ Interv. & Median & $95 \%$ Interv. \\
\hline Degree habit formation & $\eta$ & .582 & {$[.511, .663]$} & .618 & {$[.528, .693]$} \\
Intertemp. elast. substitution & $\sigma^{-1}$ & .631 & {$[.485, .771]$} & .654 & {$[.529, .777]$} \\
Subjective discount factor & $\beta$ & .9984 & {$[.9977, .9992]$} & .9990 & {$[.9979, .9997]$} \\
& & & & & \\
Degree inflation indexation & $\gamma$ & .961 & {$[.944, .977]$} & .967 & {$[.952, .982]$} \\
Fraction non-optim. firms & $\alpha$ & .980 & {$[.950, .998]$} & .979 & {$[.949, .998]$} \\
& & & & & \\
Steady-state growth rate & $10^{2} \cdot g^{*}$ & .600 & {$[.570, .630]$} & .610 & {$[.510, .670]$} \\
Autocorr. product. growth & $\vartheta$ & .973 & {$[.921, .997]$} & .971 & {$[.910, .998]$} \\
& & & & & \\
Interest rate smoothing & $\rho$ & .833 & {$[.803, .869]$} & .840 & {$[.808, .885]$} \\
Feedback on inflation & $\varphi_{1}$ & 1.630 & {$[1.582,1.683]$} & 1.671 & {$[1.581,1.774]$} \\
Feedback on output gap & $\varphi_{2}$ & .690 & {$[.628, .731]$} & .731 & {$[.661, .804]$} \\
& & & & & \\
Inflation target: prob_up & $p_{u}$ & .386 & {$[.355, .412]$} & .362 & {$[.334, .417]$} \\
Inflation target: prob_down & $p_{d}$ & .533 & {$[.473, .594]$} & .536 & {$[.472, .598]$} \\
& & & & & \\
Drift prod. shock: std. dev. & $10^{2} \cdot \sigma_{\zeta^{g}}$ & .064 & {$[.050, .076]$} & .064 & {$[.052, .080]$} \\
Level prod. shock: std. dev. & $10^{2} \cdot \sigma_{\zeta^{z}}$ & .170 & {$[.040, .900]$} & .170 & {$[.040, .900]$} \\
Prefer. shock: std. dev. & $10^{2} \cdot \sigma_{\zeta^{u}}$ & .820 & {$[.690, .970]$} & .910 & {$[.790,1.090]$} \\
Supply shock: std. dev. & $\sigma_{\zeta^{\pi}}$ & 1.119 & {$[1.112,1.126]$} & 1.117 & {$[1.110,1.124]$} \\
Monetary shock: std. dev. & $\sigma_{\zeta^{r}}$ & 1.225 & {$[1.212,1.237]$} & 1.223 & {$[1.219,1.231]$} \\
\hline \hline
\end{tabular}


Table 3: Granger-Causality Tests

\begin{tabular}{lccc}
\hline \hline Null Hypothesis: & Obs & F-Statistic & Probability \\
\hline $\begin{array}{l}\text { Lags: } 1 \\
\pi^{*} \text { doesn't GC } g\end{array}$ & 195 & & \\
$g$ doesn't GC $\pi^{*}$ & & 1.32 & 0.25 \\
Lags: 2 & 194 & & 0.03 \\
$\quad \pi^{*}$ doesn't GC $g$ & & 1.21 & 0.30 \\
$\quad g$ doesn't GC $\pi^{*}$ & & 4.69 & 0.01 \\
Lags: 3 & 193 & & \\
$\quad \pi^{*}$ doesn't GC $g$ & & 3.54 & 0.02 \\
$g$ doesn't GC $\pi^{*}$ & & 4.86 & 0.00 \\
Lags: 4 & 192 & & \\
$\quad \pi^{*}$ doesn't GC $g$ & & 4.11 & 0.00 \\
$g$ doesn't GC $\pi^{*}$ & & 5.54 & 0.00 \\
$\quad$ Null Hypothesis: & Obs & F-Statistic & Probability \\
\hline & & & \\
Lags: 1 & 195 & & \\
$\left(r-r^{*}\right)$ doesn't GC $\pi^{*}$ & & 0.51 & 0.48 \\
$\pi^{*}$ doesn't GC $\left(r-r^{*}\right)$ & & 5.09 & 0.03 \\
Lags: 2 \\
$\left(r-r^{*}\right)$ doesn't GC $\pi^{*}$
\end{tabular}


Figure 1: Comparing policy conduct under alternative rules: posterior distributions
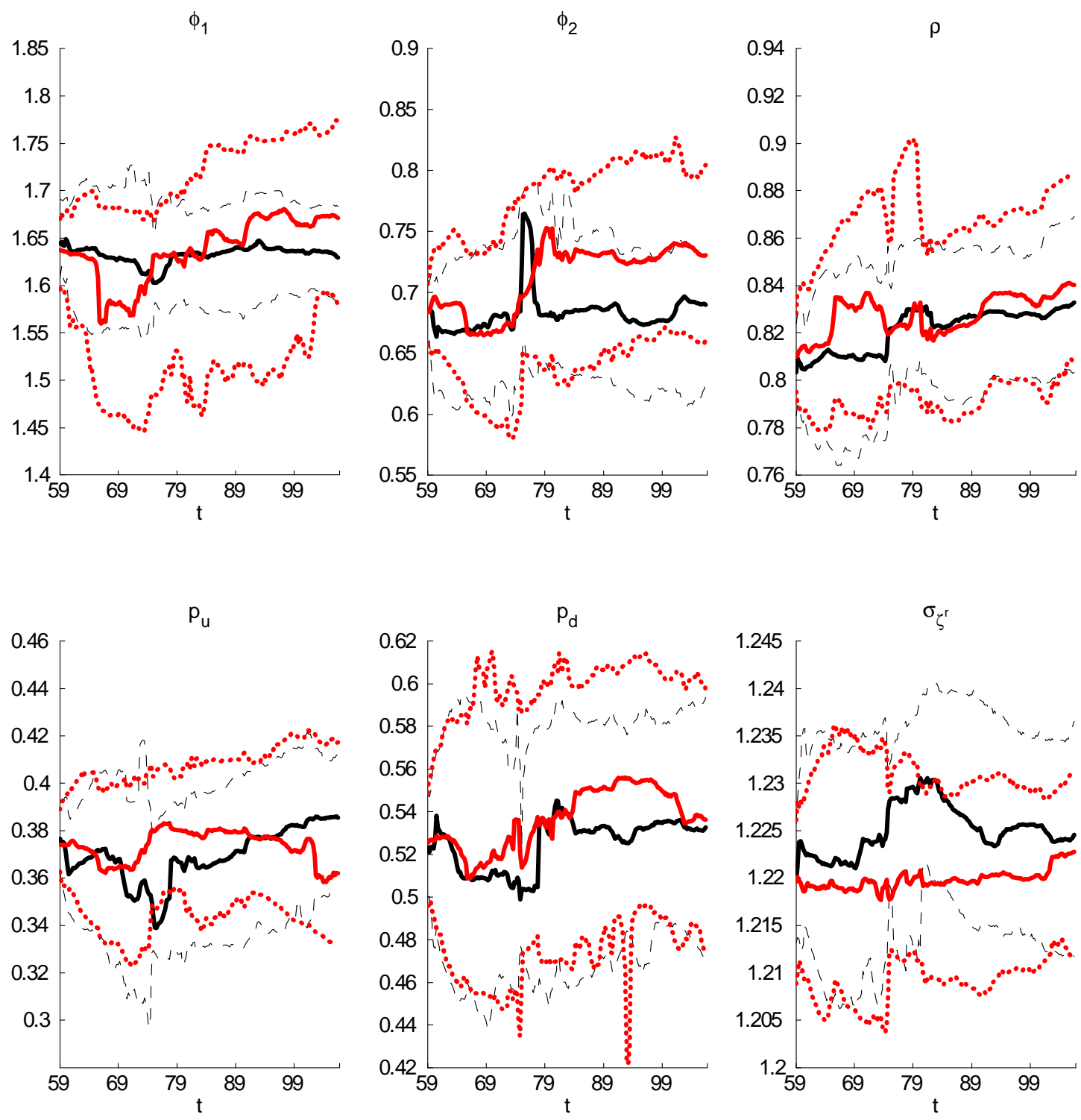
Figure 2: Comparing model parameters under alternative rules: posterior distributions
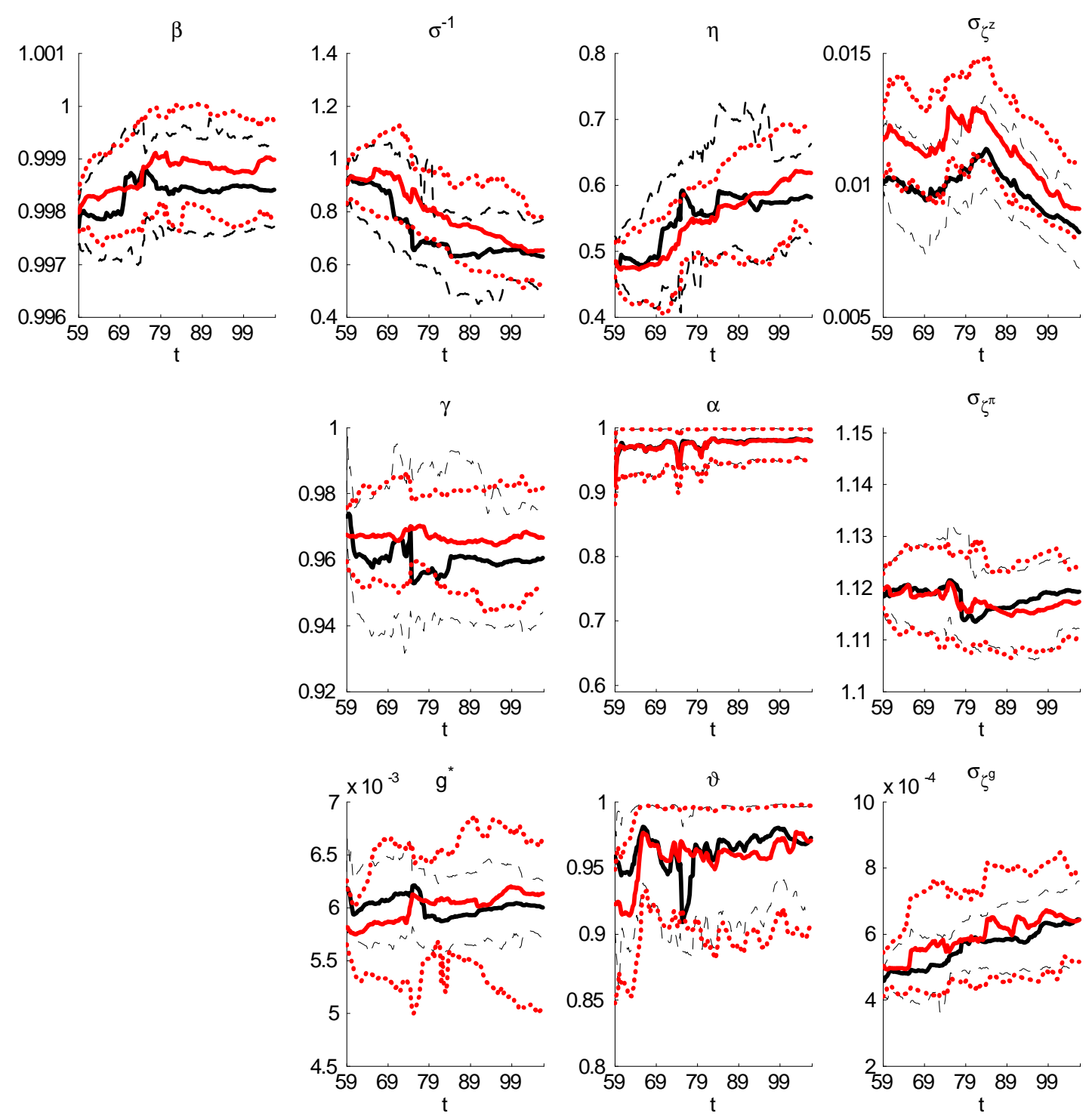
Figure 3: Estimated time-varying unobservable state variables
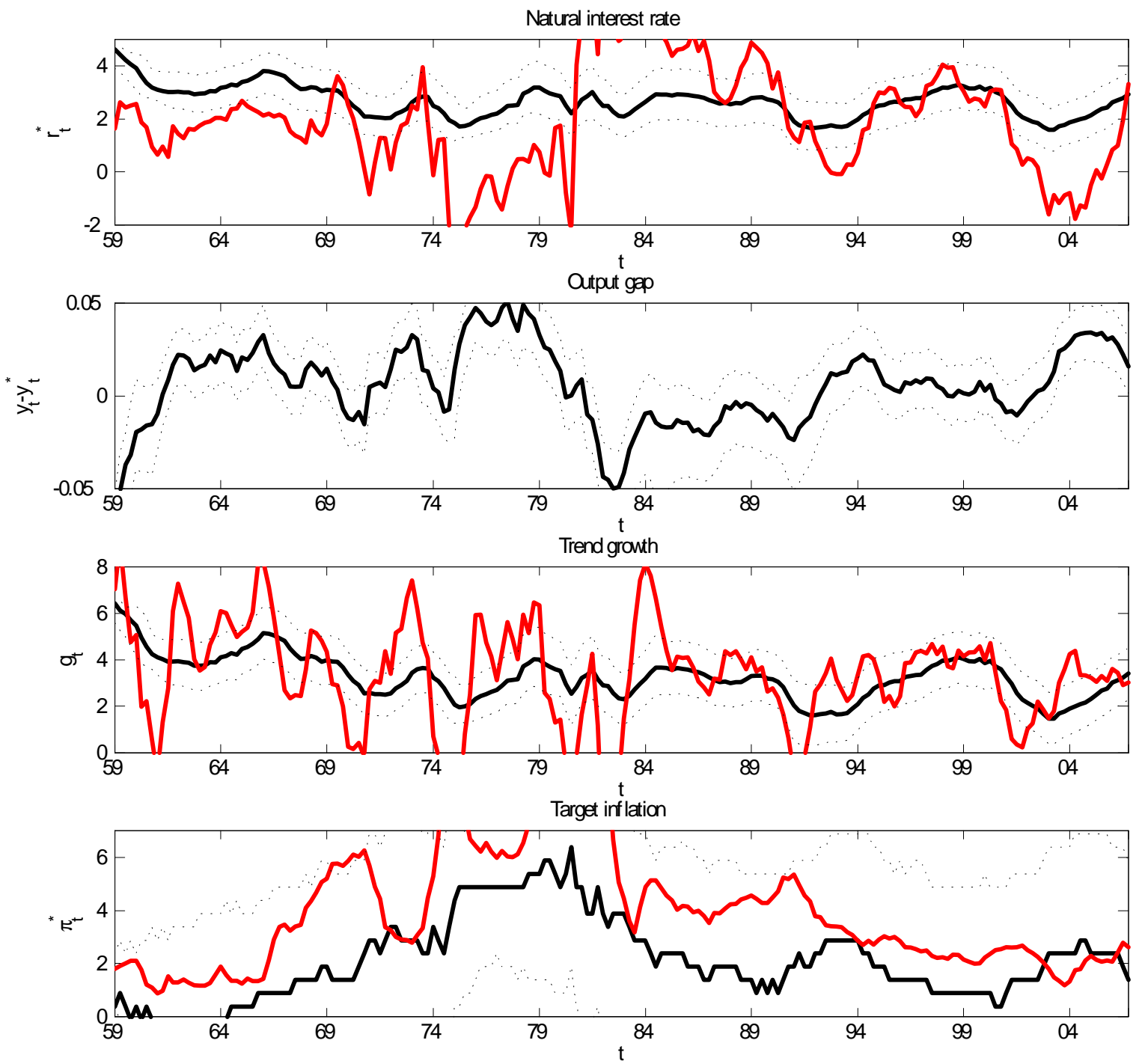

$\longrightarrow$ posterior median $\longrightarrow$ actual …2 25 posterior percentile

97.5 posterior percentile 
Figure 4: Comparing alternative estimates of the US (real) natural rate
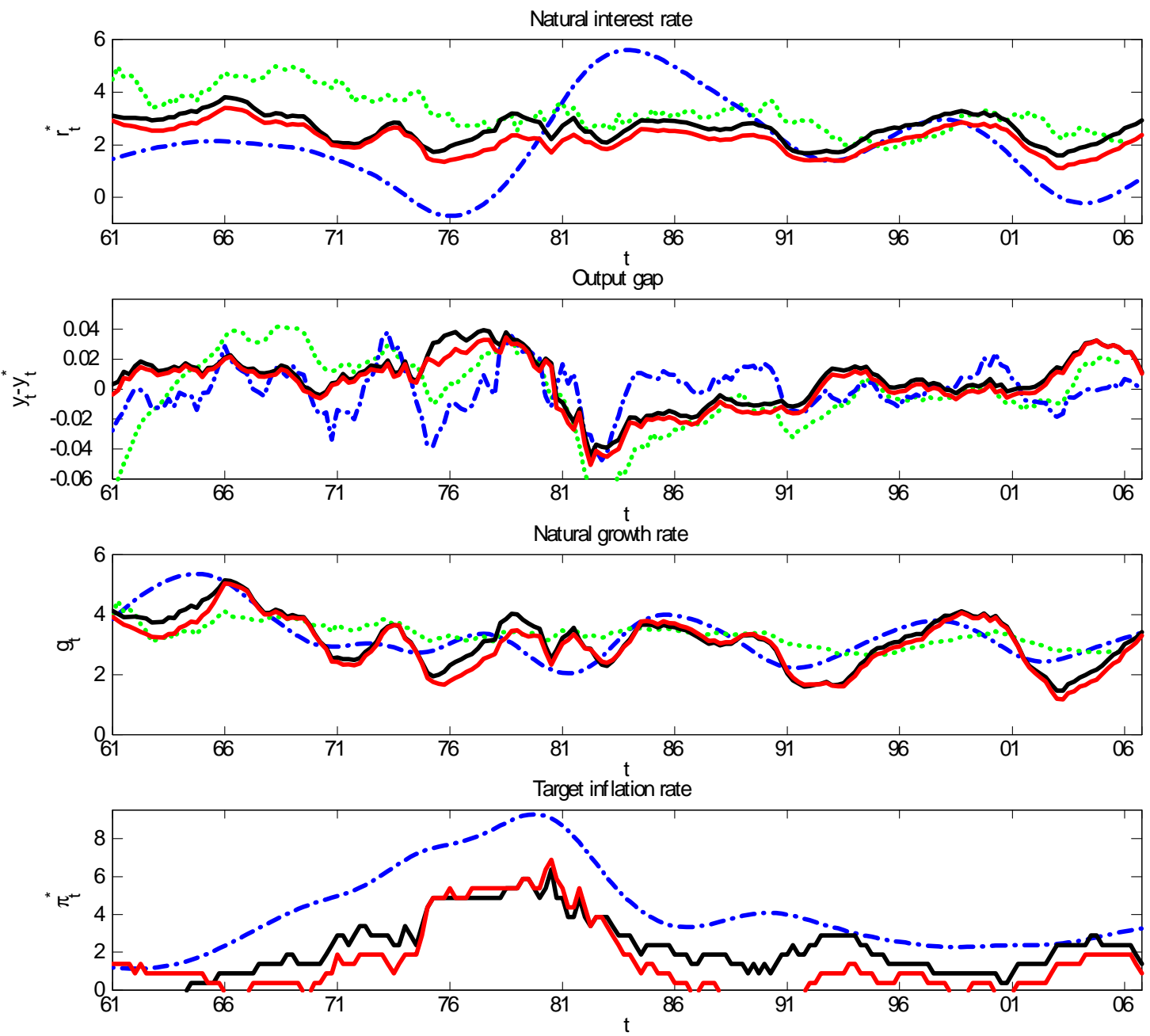
Figure 5: Posterior predictive checks: fit, serial correlation, and standard deviation 1/

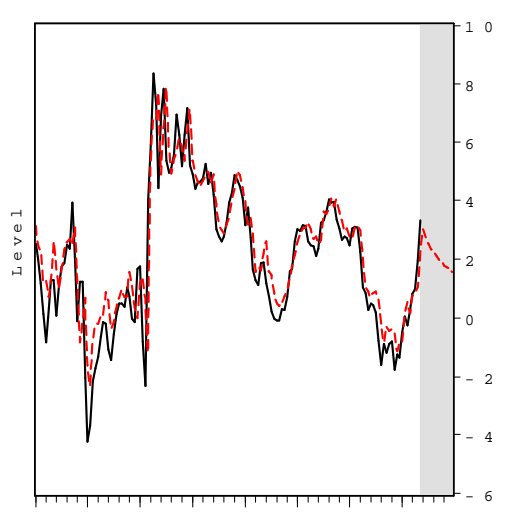

$\boldsymbol{C}_{\mathrm{R}} \boldsymbol{- \cdots}_{\mathrm{RF}}$

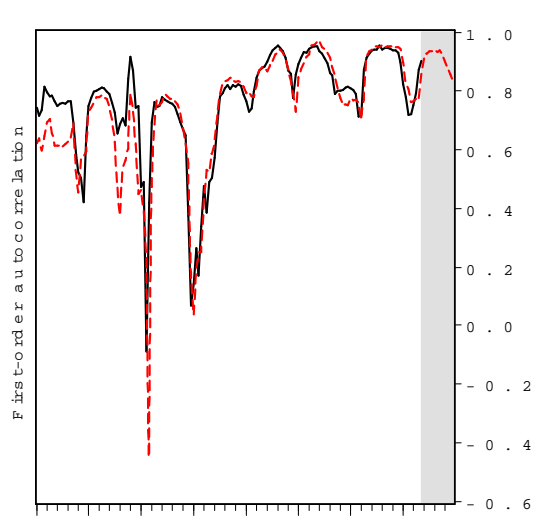

$\begin{array}{llllllllllllll}70 & 75 & 8 & 0 & 85 & 90 & 95 & 0 & 0 & 0 & 5\end{array}$

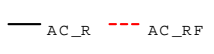

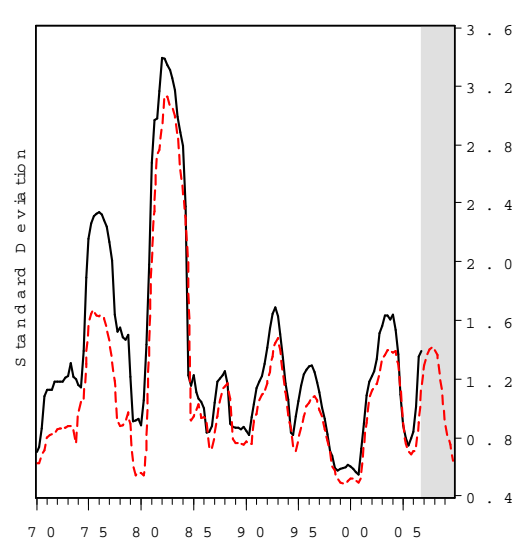

- STD_R --- STD_RF

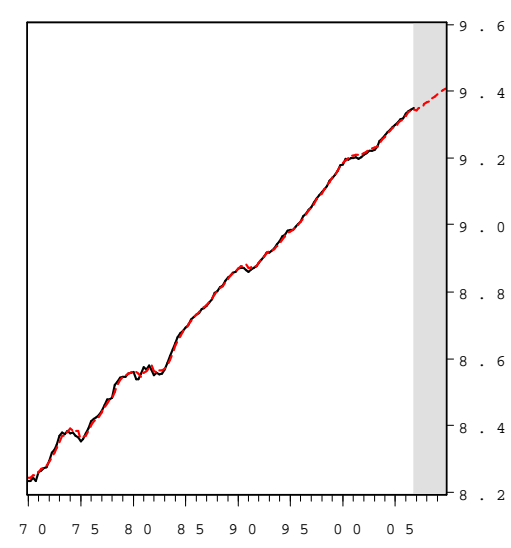

${ }^{X}{ }^{---}{ }_{Y E}$

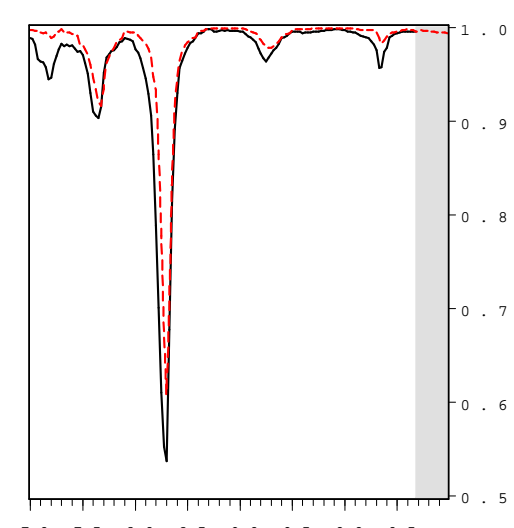

$-{ }_{\mathrm{AC} \_\mathrm{X}}-\mathrm{AC}_{-\mathrm{YF}}$

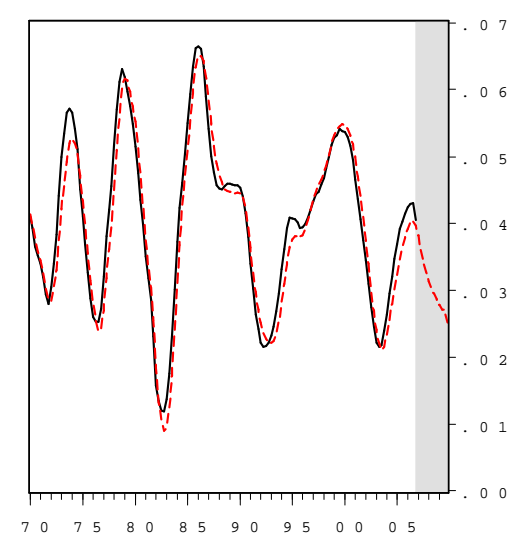

$-Y---S T D \_Y F$

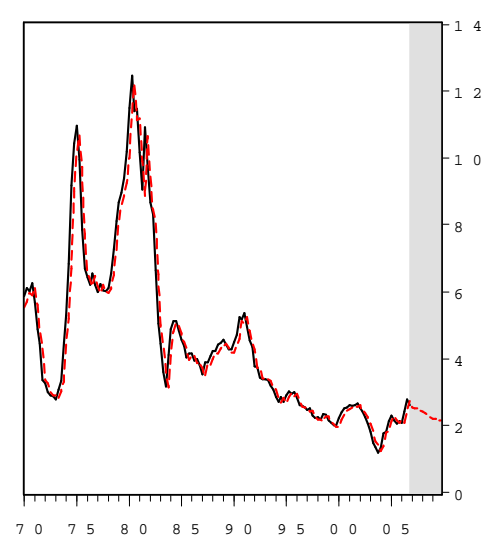

- ${ }_{P I}^{---}{ }_{P F}$
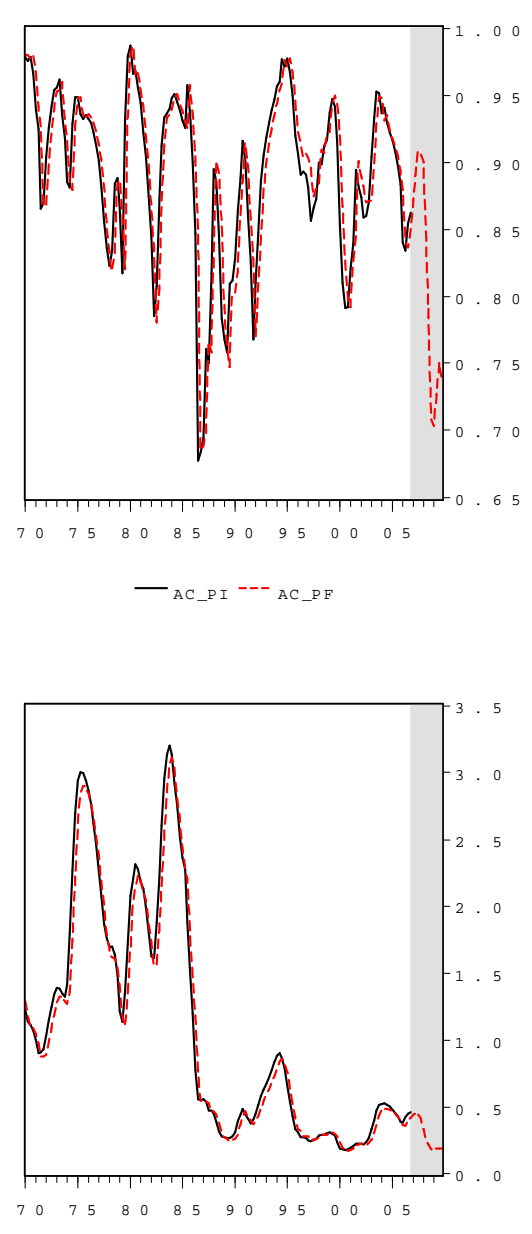

- STD_PI --- STD_PF 
Figure 6: Out-of-sample multi-step-ahead forecast probability distributions

Growth Rule
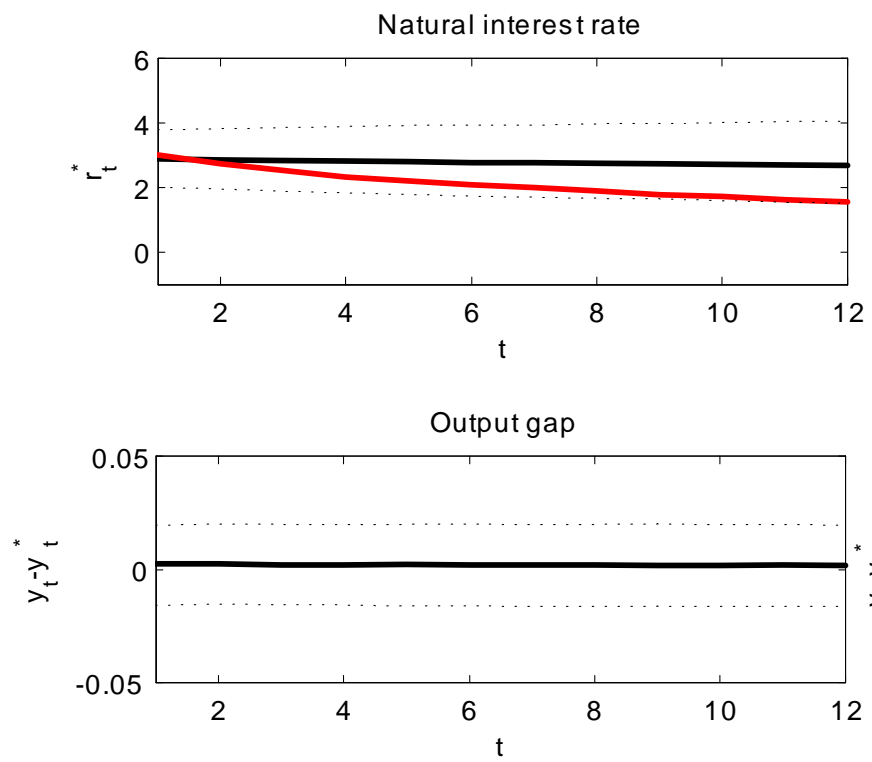

Trend growth

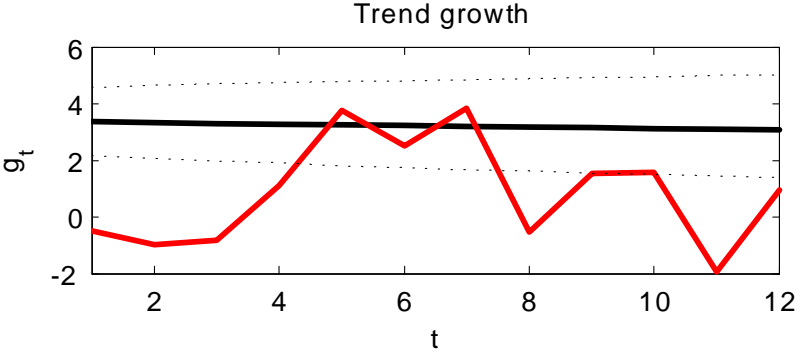

Target inflation

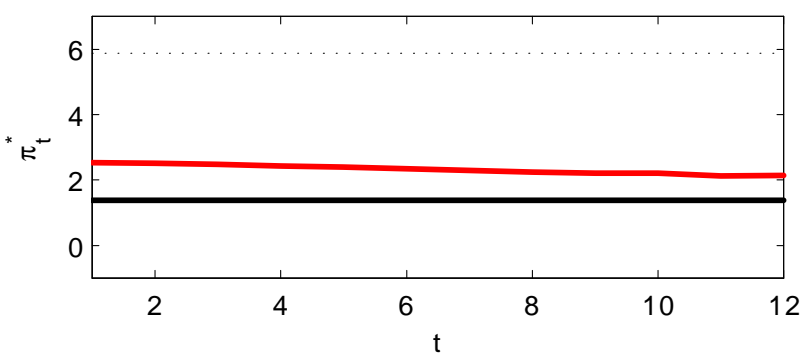

"natural level" predict. mediant

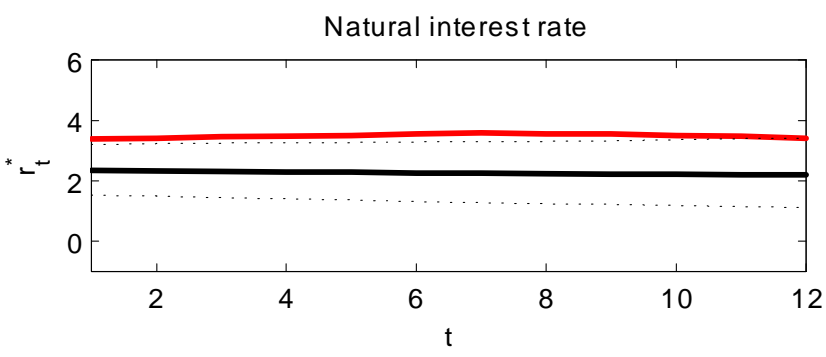

Output gap

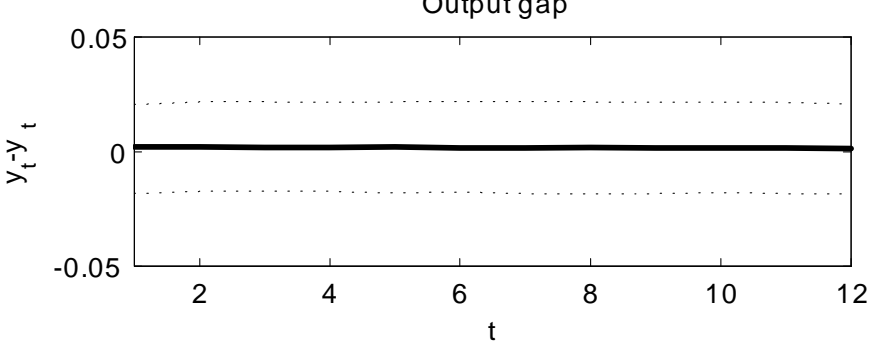

Trend growth

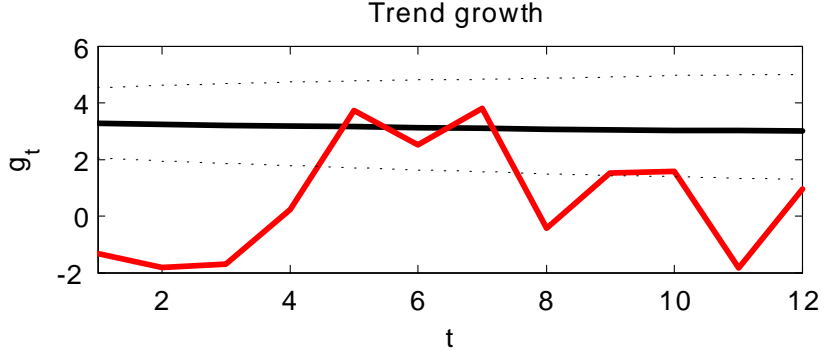

Target inflation

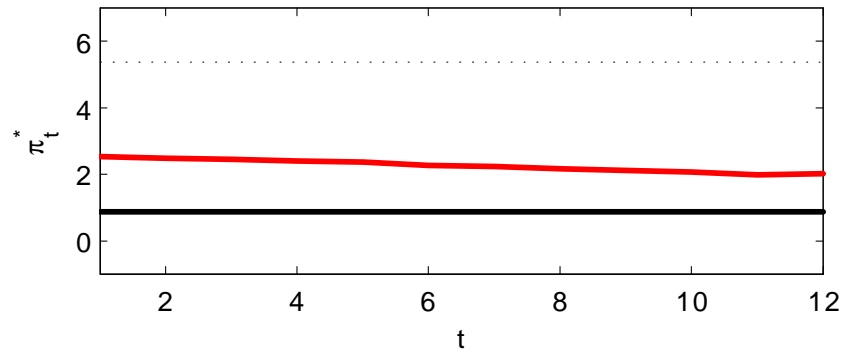

95 pct. "natural level" predict. distribution 
Figure 7: Sources of uncertainty in the interest gap forecast distribution
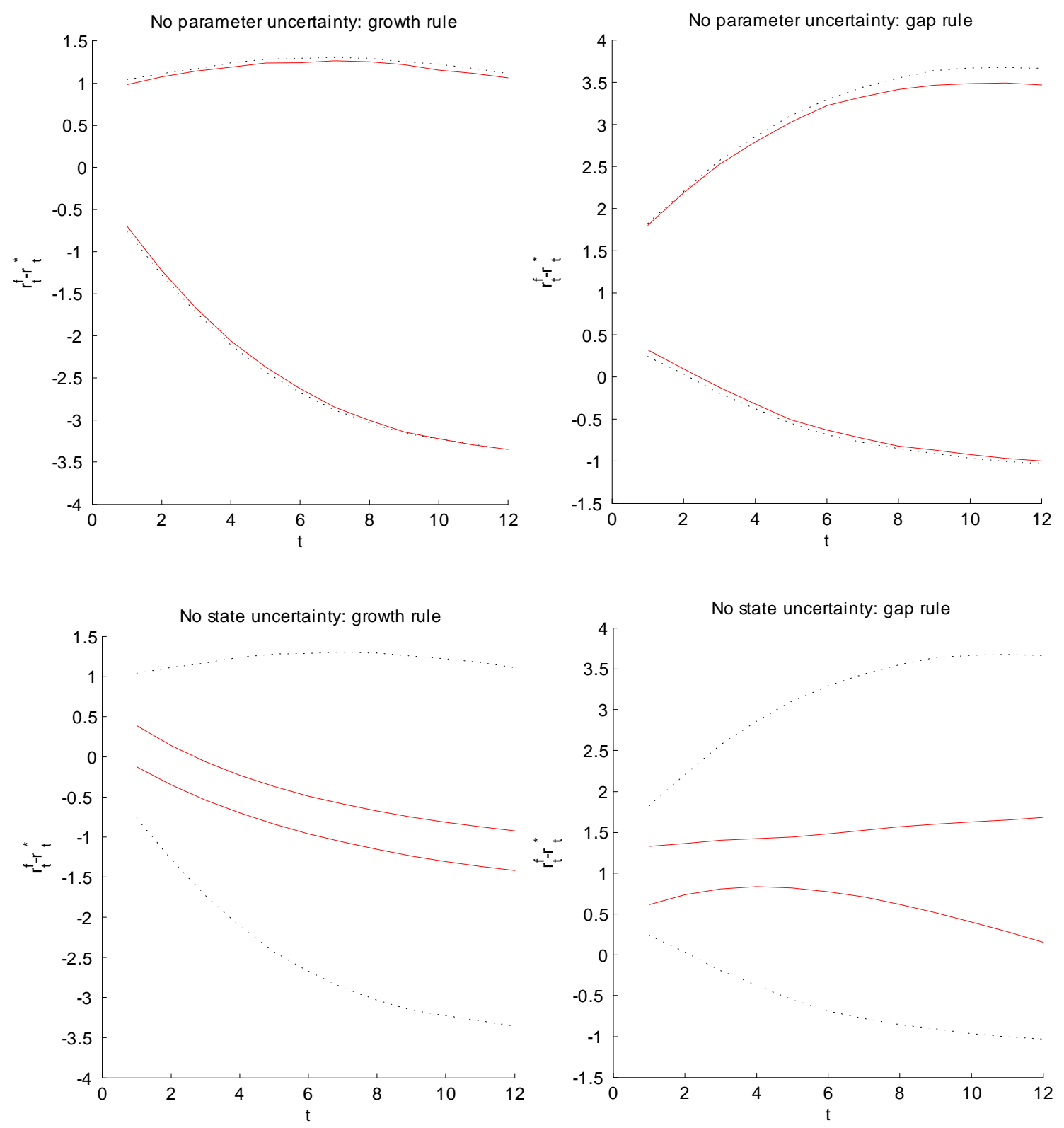


\section{European Central Bank Working Paper Series}

For a complete list of Working Papers published by the ECB, please visit the ECB's website (http://www.ecb.int)

748 "Financial dollarization: the role of banks and interest rates" by H. S. Basso, O. Calvo-Gonzalez and M. Jurgilas, May 2007.

749 "Excess money growth and inflation dynamics" by B. Roffia and A. Zaghini, May 2007.

750 "Long run macroeconomic relations in the global economy” by S. Dées, S. Holly, M. H. Pesaran and L.V. Smith, May 2007.

751 "A look into the factor model black box: publication lags and the role of hard and soft data in forecasting GDP” by M. Bańbura and G. Rünstler, May 2007.

752 "Econometric analyses with backdated data: unified Germany and the euro area" by E. Angelini and M. Marcellino, May 2007.

753 “Trade credit defaults and liquidity provision by firms" by F. Boissay and R. Gropp, May 2007.

754 "Euro area inflation persistence in an estimated nonlinear DSGE model" by G.Amisano and O.Tristani, May 2007.

755 "Durable goods and their effect on household saving ratios in the euro area" by J. Jalava and I. K. Kavonius, May 2007.

756 “Maintaining low inflation: money, interest rates, and policy stance” by S. Reynard, May 2007.

757 "The cyclicality of consumption, wages and employment of the public sector in the euro area" by A. Lamo, J.J. Pérez and L. Schuknecht, May 2007.

758 "Red tape and delayed entry" by A. Ciccone and E. Papaioannou, June 2007.

759 "Linear-quadratic approximation, external habit and targeting rules" by P. Levine, J. Pearlman and R. Pierse, June 2007.

760 "Modelling intra- and extra-area trade substitution and exchange rate pass-through in the euro area" by A. Dieppe and T.Warmedinger, June 2007.

76I "External imbalances and the US current account: how supply-side changes affect an exchange rate adjustment” by P. Engler, M. Fidora and C. Thimann, June 2007.

762 "Patterns of current account adjustment: insights from past experience" by B.Algieri and T. Bracke, June 2007.

763 "Short- and long-run tax elasticities: the case of the Netherlands" by G.Wolswijk, June 2007.

764 "Robust monetary policy with imperfect knowledge" by A. Orphanides and J. C.Williams, June 2007. 
765 “Sequential optimization, front-loaded information, and U.S. consumption” by A.Willman, June 2007.

766 "How and when do markets tip? Lessons from the Battle of the Bund" by E. Cantillon and P.-L.Yin, June 2007.

767 “Explaining monetary policy in press conferences” by M. Ehrmann and M. Fratzscher, June 2007.

768 "A new approach to measuring competition in the loan markets of the euro area" by M. van Leuvensteijn, J.A. Bikker,A. van Rixtel and C. Kok Sørensen, June 2007.

769 “The 'Great Moderation’ in the United Kingdom” by L. Benati, June 2007.

770 "Welfare implications of Calvo vs. Rotemberg pricing assumptions" by G. Lombardo and D. Vestin, June 2007.

77I "Policy rate decisions and unbiased parameter estimation in typical monetary policy rules" by J. Podpiera, June 2007.

772 "Can adjustment costs explain the variability and counter-cyclicality of the labour share at the firm and aggregate level?" by P. Vermeulen, June 2007.

773 "Exchange rate volatility and growth in small open economies at the EMU periphery" by G. Schnabl, July 2007.

774 "Shocks, structures or monetary policies? The euro area and US after 200 I" by L. Christiano, R. Motto and M. Rostagno, July 2007.

775 "The dynamic behaviour of budget components and output” by A. Afonso and P. Claeys, July 2007.

776 “Insights gained from conversations with labor market decision makers” by T. F. Bewley, July 2007.

777 “Downward nominal wage rigidity in the OECD” by S. Holden and F.Wulfsberg, July 2007.

778 “Employment protection legislation and wages” by M. Leonardi and G. Pica, July 2007.

779 "On-the-job search and the cyclical dynamics of the labor market” by M. U. Krause and T. A. Lubik, July 2007.

780 "Dynamics and monetary policy in a fair wage model of the business cycle" by D. de la Croix, G. de Walque and R.Wouters, July 2007.

78I "Wage inequality in Spain: recent developments" by M. Izquierdo and A. Lacuesta, July 2007.

782 "Panel data estimates of the production function and product and labor market imperfections" by S. Dobbelaere and J. Mairesse, July 2007.

783 "The cyclicality of effective wages within employer-employee matches: evidence from German panel data" by S.Anger, July 2007.

784 "Understanding the dynamics of labor shares and inflation" by M. Lawless and K.Whelan, July 2007.

785 “Aggregating Phillips curves” by J. Imbs, E. Jondeau and F. Pelgrin, July 2007. 
786 "The economic impact of merger control: what is special about banking?" by E. Carletti, P. Hartmann and S. Ongena, July 2007.

787 "Finance and growth: a macroeconomic assessment of the evidence from a European angle" by E. Papaioannou, July 2007.

788 "Evaluating the real effect of bank branching deregulation: comparing contiguous counties across U.S. state borders" by R. R. Huang, July 2007.

789 "Modeling the impact of external factors on the euro area's HICP and real economy: a focus on pass-through and the trade balance" by L. Landolfo, July 2007.

790 "Asset prices, exchange rates and the current account" by M. Fratzscher, L. Juvenal and L. Sarno, August 2007.

791 "Inquiries on dynamics of transition economy convergence in a two-country model” by J. Brůha and J. Podpiera, August 2007.

792 "Euro area market reactions to the monetary developments press release" by J. Coffinet and S. Gouteron, August 2007.

793 "Structural econometric approach to bidding in the main refinancing operations of the Eurosystem" by N. Cassola, C. Ewerhart and C. Morana, August 2007.

794 (Un)naturally low? Sequential Monte Carlo tracking of the US natural interest rate" by M. J. Lombardi and S. Sgherri, August 2007. 


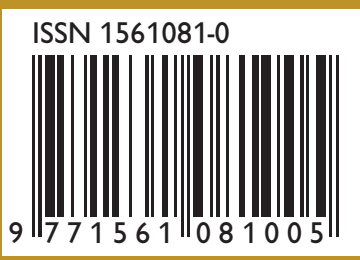

